\title{
Electrochemical Characterization of Nanoporous Nickel Oxide Thin Films Spray-Deposited onto Indium-Doped Tin Oxide for Solar Conversion Scopes
}

\author{
Muhammad Awais, ${ }^{1}$ Denis P. Dowling, ${ }^{2}$ Franco Decker, ${ }^{3}$ and Danilo Dini ${ }^{3}$ \\ ${ }^{1}$ Department of Industrial Engineering, King Abdulaziz University, P.O. Box 344, Rabigh 21911, Saudi Arabia \\ ${ }^{2}$ School of Chemical and Bioprocess Engineering, University College Dublin, Belfield, Dublin 4, Ireland \\ ${ }^{3}$ Department of Chemistry, University of Rome "La Sapienza", Piazzale Aldo Moro 5, 00185 Rome, Italy \\ Correspondence should be addressed to Danilo Dini; danilo.dini@uniromal.it
}

Received 29 April 2015; Accepted 26 July 2015

Academic Editor: Jörg Fink

Copyright (C) 2015 Muhammad Awais et al. This is an open access article distributed under the Creative Commons Attribution License, which permits unrestricted use, distribution, and reproduction in any medium, provided the original work is properly cited.

\begin{abstract}
Nonstoichiometric nickel oxide $\left(\mathrm{NiO}_{x}\right)$ has been deposited as thin film utilizing indium-doped tin oxide as transparent and electrically conductive substrate. Spray deposition of a suspension of $\mathrm{NiO}_{x}$ nanoparticles in alcoholic medium allowed the preparation of uniform $\mathrm{NiO}_{x}$ coatings. Sintering of the coatings was conducted at temperatures below $500^{\circ} \mathrm{C}$ for few minutes. This scalable procedure allowed the attainment of $\mathrm{NiO}_{x}$ films with mesoporous morphology and reticulated structure. The electrochemical characterization showed that $\mathrm{NiO}_{x}$ electrodes possess large surface area (about 1000 times larger than their geometrical area). Due to the openness of the $\mathrm{NiO}_{x}$ morphology, the underlying conductive substrate can be contacted by the electrolyte and undergo redox processes within the potential range in which $\mathrm{NiO}_{x}$ is electroactive. This requires careful control of the conditions of polarization in order to prevent the simultaneous occurrence of reduction/oxidation processes in both components of the multilayered electrode. The combination of the open structure with optical transparency and elevated electroactivity in organic electrolytes motivated us to analyze the potential of the spray-deposited $\mathrm{NiO}_{x}$ films as semiconducting cathodes of dye-sensitized solar cells of p-type when erythrosine B was the sensitizer.
\end{abstract}

\section{Introduction}

Nickel oxide $\left(\mathrm{NiO}_{x}\right)$ is a semiconducting material that displays p-type conductivity with values of the order of $10^{-4}$ $10^{-2} \mathrm{~S} \mathrm{~cm}^{-1}$ at room temperature [1]. The existence of a range of conductivities is a consequence of the dependence of the electrical conductivity on the concentration of $\mathrm{Ni}(\mathrm{III})$ centers that act as hole carriers [2]. The concentration of Ni(III) centers in the oxide determines the value of $x$ in the formula of the nonstoichiometric oxide $\mathrm{NiO}_{x}$, with $x$ being comprised in the range $1<x<1.5$. The amount of $\mathrm{Ni}$ (III) centers in the oxide and henceforth the metal oxide conductivity can be also varied through the addition of doping agents like monovalent cations, for example, $\mathrm{Li}^{+}$, which are introduced in the structure of $\mathrm{NiO}_{x}$ during the procedure of oxide preparation [3]. Alternatively, $\mathrm{Ni}(\mathrm{III})$ centers can be injected electrochemically in the preformed metal oxide structure provided that nickel oxide possesses the configuration of thin film (thickness, $l$, range: $0.2<l<6 \mu \mathrm{m}$ ) and is deposited onto a conductive substrate [4-9]. Another characteristic of $\mathrm{NiO}_{x}$ thin films $(l<4 \mu \mathrm{m})$ is the optical transparency within the visible spectrum with $\mathrm{NiO}_{x}$ lacking any absorption peak in the same spectral range (colorless material) [10]. This combination of electrical and optical properties has allowed the successful employment of $\mathrm{NiO}_{x}$ as active material in electrochromic devices [11]. Besides electrochromism, $\mathrm{NiO}_{x}$ thin films have been profitably employed also as photoactive cathodes of dye-sensitized solar cells (DSCs) [12] of p-type [13-16], or in tandem configuration [13, 17, 18]. For these electrochemical applications, nickel oxide films have been prepared in a variety of ways that include ion sputtering [4], microblasting [5], electrochemical deposition [19], spray 
pyrolysis [20], or sol-gel method [9]. In the present contribution, we have considered the preparation of mesoporous $\mathrm{NiO}_{x}$ in the configuration of thin films through the spray deposition of a suspension of $\mathrm{NiO}$ nanoparticles onto ITO substrates and the successive sintering of the sprayed deposit either in conventional furnace [6] or in plasma atmosphere [7]. The two differently sintered nickel oxide samples in the following are distinguished with CS (conventionally sintered) [6] and RDS (rapid discharge sintering) $\mathrm{NiO}_{x}$ [7]. The electrochemical characterization of CS and RDS nickel oxide here deposited on ITO substrate is presented in a comparative fashion. Such a type of analysis is made necessary to verify the correctness of the procedure of deposition which has to afford electroactive $\mathrm{NiO}_{x}$ with high surface area (characteristic of mesoporosity), with electrical connectivity between the sintered nanoparticles (characteristic of reticulation), and with electrical contact as well as mechanical adhesion between the $\mathrm{NiO}_{x}$ layer and the underlying ITO substrate. Recently, we demonstrated the feasibility of the procedure of conventional sintering for the deposition of mesoporous $\mathrm{NiO}_{x}$ onto ITO when CS $\mathrm{NiO}_{x}$ had to be employed as photoactive cathode of p-type DSCs [6]. In the present contribution, we will demonstrate for the first time that RDS procedure will also produce electroactive layers of nickel oxide in both bare and erythrosine (ERY) B sensitized state when ITO is the technical substrate $[13,21,22]$. We will also show that the resulting RDS samples represent excellent candidates for $\mathrm{p}$ type DSCs since they displayed one of the highest values of open circuit photovoltage with the dye ERY $\left(V_{\mathrm{OC}}=\right.$ $126 \mathrm{mV}$, vide infra). The advantages of the RDS method for electroactive thin layers deposition consist mainly in the scalability, rapidity of procedure, easiness of the steps of surface cleaning and additives removal, and economy of the process of deposition in terms of energetic costs [7].

\section{Experimental Part}

2.1. Deposition of $\mathrm{NiO}_{x}$ Coatings. Nanostructured $\mathrm{NiO}_{x}$ coatings with thicknesses ranging in the interval $0.2-4 \mu \mathrm{m}$ were obtained by spraying back and forth a suspension of $\mathrm{NiO}$ nanopowder (diameter $<50 \mathrm{~nm}$, from Sigma-Aldrich) onto ITO [23]. NiO nanopowder was dispersed in alcoholic medium. After spraying the $\mathrm{NiO}$ coated substrate was sintered with two different procedures: (i) conventional sintering (CS) and (ii) rapid discharge sintering (RDS). The procedural details and the experimental setups used for the sintering of the sprayed $\mathrm{NiO}_{x}$ coatings have been reported in $[6,7]$ for the CS and RDS modalities, respectively. A circumferential antenna plasma (CAP) microwave system [24] was utilized to carry out the RDS procedure. In the microwave chamber, a pressure of 5 mbar was maintained using a gas mixture of $\mathrm{Ar}$ and $\mathrm{O}_{2}$ in the molar ratio $10: 1$. A Mugge microwave power supply working at a frequency of $2.45 \mathrm{GHz}$ was used as power generator (input power: $2.4 \mathrm{~kW}$ ) to create the plasma atmosphere. The temperature of the working specimens was measured in situ during the RDS heat treatment with a LASCON QP003 two-color pyrometer (from Dr. Merganthaler $\mathrm{GmbH} \& \mathrm{Co}$.). The CS procedure was conducted in air with a Carbolite Furnace (RHF 1200). The maximum temperature of sintering was $450^{\circ} \mathrm{C}$ in both CS and RDS procedures. The spray deposition of $\mathrm{NiO}_{x}$ nanoparticles onto ITO substrate is conducted at room temperature. Therefore, the ITO substrate does not undergo any thermal treatment during the step of spray deposition of the dispersed nanopowder. The ITO-covered glass panels from Balzers were square-shaped and had an area of $25 \mathrm{~cm}^{2}$. The description of the experimental setup for spraying the suspension of the $\mathrm{NiO}$ nanopowder has been reported in [25]. The mass concentration of the $\mathrm{NiO}_{x}$ nanoparticles in the alcoholic dispersion was $20 \mathrm{mg} \mathrm{mL}^{-1}$ (medium: 2-propanol, from Sigma-Aldrich). All chemicals were used as received and were not subjected to any further process of purification. After sintering at $450^{\circ} \mathrm{C}$ the electrical transport properties of underlying ITO were checked. No significant loss of electrical conductivity could be observed upon sample heating in comparison to untreated ITO substrate. ITO conductivity was above $10^{2} \mathrm{~S} \mathrm{~cm}^{-1}$.

2.2. Morphology Characterization Equipment. The microscopic analyses of the $\mathrm{NiO}_{x}$ films were carried out using a FEI Quanta 3D FEG DualBeam (FEI Ltd., Hillsboro, USA) focused ion beam/scanning electron microscope (FIB/SEM) system [6]. The as-deposited $\mathrm{NiO}_{x}$ films were preventively coated with platinum via sputtering using an Emitech K575X sputter coating unit prior to any taking of the SEM pictures. This step was done in order to prevent surface charging by the scanning electron beam.

2.3. Sensitization of $\mathrm{NiO}_{x}$ Coatings. Prior to the step of sensitization the RDS and $\mathrm{CS} \mathrm{NiO}_{x}$ films deposited onto ITO were rinsed with ethanol and heated up to $400^{\circ} \mathrm{C}$ for few minutes. The samples of $\mathrm{NiO}_{x}$ were allowed to cool down to $100^{\circ} \mathrm{C}$, and at that temperature they were immersed in the sensitizer solution [0.3 mM ERY in ethanol (from Fisher)] for 16 hours. $\mathrm{NiO}_{x}$ dipping was carried out at room temperature. ERY sensitizer was purchased from Sigma-Aldrich. After removing the electrode from the tincture solution the sensitized electrode was washed with pure ethanol to remove the nonchemisorbed dye molecules.

\subsection{Electrochemical Characterization of Uncoated ITO.} Uncoated ITO was utilized as working electrode in a threeelectrode cell (vide infra) to analyze the electrochemical properties of the bare substrate. The purpose of this analysis is the identification of the potential ranges in which ITO film becomes electroactive and can be either oxidized or reduced $[6,26]$. Prior to any electrochemical test bare ITO was kept in ultrasonic bath using isopropyl alcohol as solvent. Ultrasonic treatment lasted 30 mins. Successively the ultrasonically cleaned ITO was dried in oven at $60^{\circ} \mathrm{C}$. After the cleaning treatment the ITO substrate was introduced in an Ar filled glove box. The uncoated ITO substrate was manipulated in the glove box for cell assembly utilizing a three-electrode cell with $\mathrm{Li}$ rods (from Sigma-Aldrich) as counter and reference electrodes [27] and $0.7 \mathrm{M} \mathrm{LiClO}_{4}$ (from SigmaAldrich) in anhydrous propylene carbonate (from Fisher) as 
electrolyte. For the electrochemical characterization of ITO the potential values will be referred to the $\mathrm{Li}^{+} / \mathrm{Li}$ redox couple. Chemicals for the definition of the electrolyte were used as received and were stored in an Ar filled glove box from Innovative Technology (Newburyport, Massachusetts, USA). Inside the glove box the content of $\mathrm{O}_{2}$ and $\mathrm{H}_{2} \mathrm{O}$ was below $10 \mathrm{ppm}$ and $5 \mathrm{ppm}$, respectively. The electrochemical cell was assembled under Ar atmosphere inside the glove box. A supernatant Ar atmosphere was maintained in the cell during the electrochemical experiments. Cyclic voltammetries and electrochemical impedance spectroscopy (EIS) experiments were carried out with an electrochemical analyzer (model 604C) from CH Instruments (Austin, Texas, USA). EI spectra were recorded within the frequency range $5 * 10^{-3}-1 * 10^{5} \mathrm{~Hz}$ in going from the highest to the lowest frequency.

2.5. Electrochemical Characterization of $\mathrm{NiO}_{x}$ Coatings. The electrochemical characterization of the differently sintered $\mathrm{NiO}_{x}$ coatings was carried out in cells with three-electrode configuration. The working electrode was glass/ITO/CS $\mathrm{NiO}_{x}$ or glass/ITO/RDS $\mathrm{NiO}_{x}$ and their ERY-sensitized versions. Li rods were used as counter and reference electrodes. The electrolyte was the same as the one used for the electrochemical tests of uncoated ITO. Also in the case of the electrochemical characterization of $\mathrm{NiO}_{x}$ thin films the potential values will be referred to the redox couple $\mathrm{Li}^{+} / \mathrm{Li}$. Cyclic voltammetries and EIS experiments were conducted with the same setup utilized for the analysis of the electrochemical properties of uncoated ITO (electrochemical workstation from CH Instruments).

2.6. DSCs Preparation. The ERY-sensitized films of RDS and CS $\mathrm{NiO}_{x}$ (the photoelectroactive electrodes) were sealed face-to-face in a sandwich configuration with a platinised FTO counter electrode using $30 \mu \mathrm{m}$ thick precut Surlyn thermoplastic frame $(6 \times 6 \mathrm{~mm}$ interior $)$ having the function of sealant and interelectrode spacer [18]. The sandwiched device was filled with the electrolyte formed by $0.1 \mathrm{M} \mathrm{I}_{2}$ and $1.0 \mathrm{M} \mathrm{LiI}$ in acetonitrile. $\mathrm{I}_{2}$, LiI, and acetonitrile were purchased from Sigma-Aldrich and were used as received. The electrolyte was inserted through a predrilled hole in the counter electrode using an injection procedure at reduced pressure. The hole was sealed with Surlyn and a glass cover slide.

\section{Results and Discussion}

3.1. Electrochemical Behavior of ITO Substrate. We have previously shown that technical ITO with nominal sheet resistance of $15 \Omega / \square$ and thickness $0.1 \mu \mathrm{m}$ is electroactive in nonaqueous electrolyte [6] and displays an irreversible wave of reduction between 1.2 and $3.7 \mathrm{~V}$ versus $\mathrm{Li}^{+} / \mathrm{Li}$ (Figure 1).

Such an electrochemical behavior has been attributed to the initial irreversible uptake of lithium cations inside $n$ doped ITO according to the process [28]:

$$
n-\mathrm{Sn}_{x} \mathrm{In}_{2-x} \mathrm{O}_{3}+y \mathrm{Li}^{+}+y \mathrm{e}^{-} \longrightarrow n-\mathrm{Li}_{y} \mathrm{Sn}_{x} \mathrm{In}_{2-x} \mathrm{O}_{3}
$$

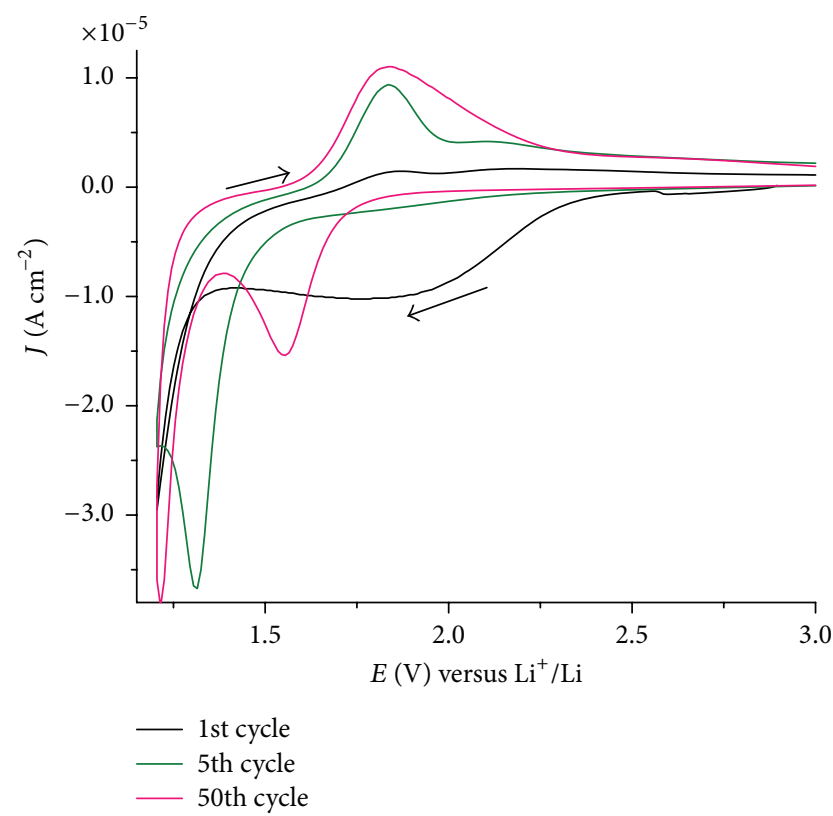

FIgURE 1: Evolution of the cyclic voltammogram of uncoated ITO. Electrolyte: $0.7 \mathrm{M} \mathrm{LiClO}_{4}$ in anhydrous propylene carbonate; counter electrode: $\mathrm{Li}$; reference redox couple: $\mathrm{Li}^{+} / \mathrm{Li}$; scan rate: $5 \mathrm{mV} \mathrm{s}^{-1}$.

The electrochemically driven phenomenon of (1) leads to the permanent rearrangement of the ITO structure as $n$ - $\mathrm{Li}_{y} \mathrm{Sn}_{x} \mathrm{In}_{2-x} \mathrm{O}_{3}$ (here abbreviated as $\mathrm{Li}_{y}$-ITO) mainly at the electrode/electrolyte interface (Figure 1). Morphological modification of the surface of $\mathrm{Li}_{y}$-ITO of the type represented in Figure 2 has been proposed when ITO potential is brought down to $1.2 \mathrm{~V}$ versus $\mathrm{Li}^{+} / \mathrm{Li}$ and then cycled between 2.7 and $1.2 \mathrm{~V}$ versus $\mathrm{Li}^{+} / \mathrm{Li}[6]$.

According to this depiction the electrochemical cycling of lithiated ITO should produce an effect of grains separation with the consequent opening of intergrain channels due to possible surface stress [29]. The latter phenomenon is generated by the retention of ionic charge on the surface of lithiated ITO. As a consequence of that, an extension of the $\mathrm{Li}_{y}$-ITO surface exposed to the electrolyte is expected (Figure 2). Such an interpretation is supported by the observation of an increase of current density upon continuous electrochemical cycling of $\mathrm{Li}_{y}$-ITO [6].

When SEM pictures of pristine ITO and electrochemically cycled ITO are confronted (Figure 3), we notice the presence of a grained supernanostructure in the morphology of electrochemically cycled ITO. Grains show linear dimensions in the order of several nanometers and present much smaller size with respect to the characteristic crystals of pristine ITO. Therefore, the morphological evolution of ITO consists of the increase of its surface area following the irreversible process of ITO lithiation (see (1) and (2)). Another important difference between pristine and electrochemically cycled ITO images is the sharpness of their corresponding SEM pictures. The more blurred image corresponds to pristine ITO. This indicates a relatively lower electrical conductivity of pristine ITO with respect to its lithiated state which, in turn, 


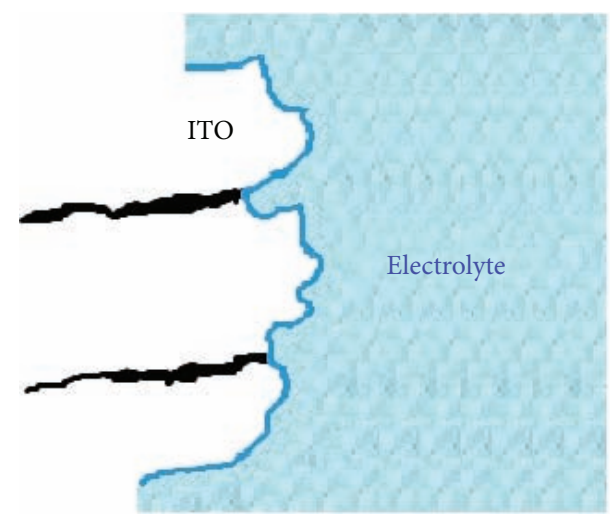

(a)

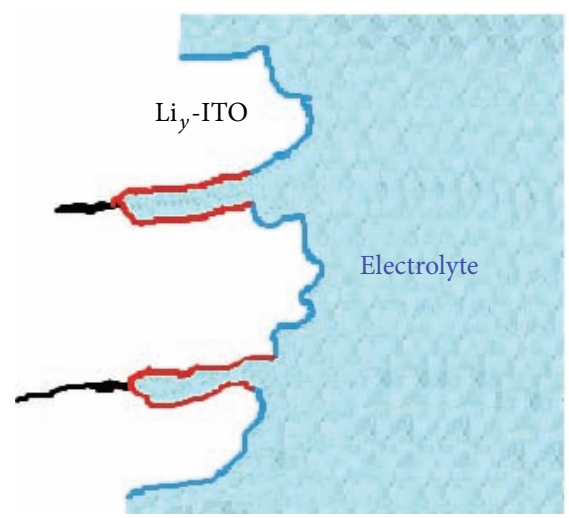

(b)

FIGURE 2: Schematic depiction of the morphological evolution of the ITO/electrolyte interface upon electrochemical cycling and consequent lithiation of the oxide. Blue lines represent the surface sections of (a) pristine ITO and (b) Li $\mathrm{i}_{y}$-ITO grains which are exposed to the electrolyte. Black lines in (a) and (b) represent the grain borders of the electrode (sectional view), which are not in contact with the electrolyte prior to lithiation. Red lines in (b) represent the expansion of the $\mathrm{Li}_{y}-\mathrm{ITO} /$ electrolyte interface (sectional view) with respect to the interface of pristine ITO prior to electrochemical cycling.

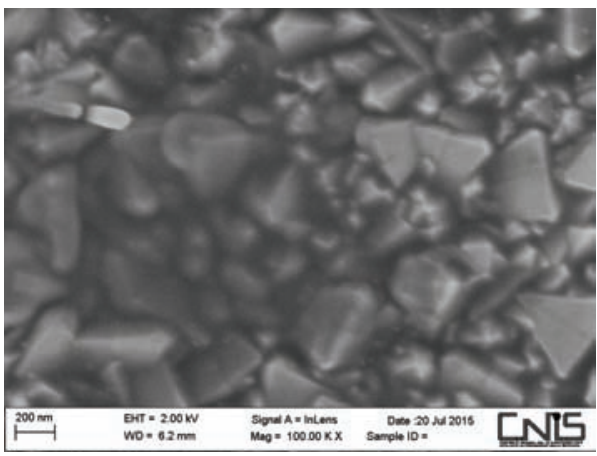

(a)

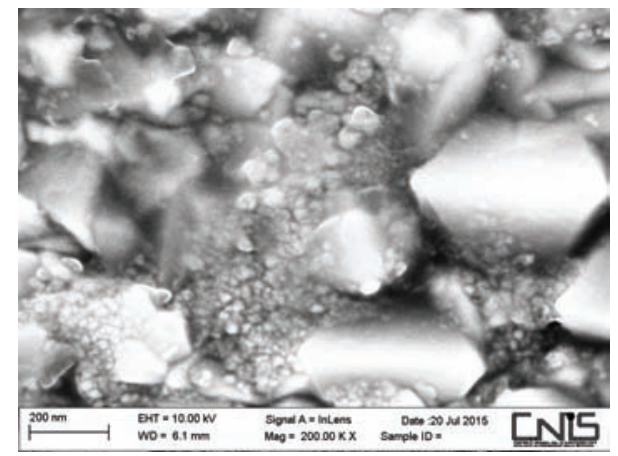

(b)

FIGURE 3: SEM pictures of (a) pristine ITO and (b) electrochemically cycled ITO after the stabilization of the voltammogram (cathodic process of Figure 1).

presents more neat contours. This difference of image quality constitutes indirect evidence of the increase of conductivity in passing from pristine to lithiated ITO due to the increase of the number of electronic and ionic charge carriers in lithiated ITO with respect to its pristine state (see (1) and (2)).

To investigate further the changes of the electron transport properties in lithiated ITO, electrochemical impedance spectroscopy (EIS) has been employed [30]. The impedance spectra have been recorded when lithiated ITO (see Figure 2) was polarized at 1.2 and $2.7 \mathrm{~V}$ versus $\mathrm{Li}^{+} / \mathrm{Li}$ in $0.7 \mathrm{M} \mathrm{LiClO}_{4}$ in anhydrous PC. Under these circumstances the electrochemical reaction is the process of lithium ions uptake and release by $\mathrm{Li}_{y}$-ITO, respectively, at 1.2 and $2.7 \mathrm{~V}$ versus $\mathrm{Li}^{+} / \mathrm{Li}$ with the accompanying uptake and release of electrons in order to preserve electrical neutrality within $\mathrm{Li}_{y}$-ITO [26]:

$$
\mathrm{Li}_{y} \mathrm{Sn}_{x} \mathrm{In}_{2-x} \mathrm{O}_{3}+z \mathrm{Li}^{+}+z \mathrm{e}^{-} \longrightarrow \mathrm{Li}_{y+z} \mathrm{Sn}_{x} \mathrm{In}_{2-x} \mathrm{O}_{3}
$$

Both EIS profiles are characterized by the succession of two semicircles with different amplitude: the smallest one at the higher frequencies (Figure 4(a)), followed by the largest one at the lower frequencies (Figure 4(b)). The highfrequency semicircle (Figure $4(\mathrm{a})$ ) is associated with the capacitance built up by the charge separation existing at the $\mathrm{Li}_{y}$-ITO/electrolyte interface (double layer capacitance, $C_{\mathrm{DL}}$ ), which is connected in parallel with the charge transfer resistance $\left(R_{\mathrm{CT}}\right)$ of ionic insertion/extraction through the same $\mathrm{Li}_{y}$-ITO/electrolyte interface. The electrical parameters associated with the uncompleted larger semicircle observed at the lower frequencies (Figure 4(b)) consist of the capacitance of the $\mathrm{Li}_{y}$-ITO layer (capacitance of the space charge layer, $C_{\mathrm{SC}}$, typical of semiconductors) [31] connected in parallel with the resistance of charge transport $\left(R_{\mathrm{Li}_{y} \mathrm{ITO}}\right)$ through the same layer (Figure 5). Due to lithiation, the charge transport through the $\mathrm{Li}_{y}$-ITO layer has to be considered of mixed nature, that is, both ionic and electronic [32]. In the present case the EIS profiles of lithiated ITO do not show diffusive Warburg elements with linear trend of the EIS response. This result is consistent with our previous finding that the electrochemical process of lithium ions uptake in $\mathrm{Li}_{y}$-ITO is surface confined and not diffusion controlled [6]. It must be said that also diffusion will take place in lithiated ITO as a transport mechanism but it is not predominant in the control of the transport properties in such a system within the range of frequencies here considered. In fact, a finite thickness 
effect would have manifested itself through the verticality of the EIS response [30], but this was not the case at least within the experimental range of adopted frequencies when $\mathrm{Li}_{y}$-ITO was polarized at 1.2 and $2.7 \mathrm{~V}$ versus $\mathrm{Li}^{+} / \mathrm{Li}$. The series resistance deriving from the contribution of the liquid electrolyte is not shown. From the analysis of the EIS profiles we found that $R_{\mathrm{CT}}$ of $\mathrm{Li}_{y}$-ITO increases considerably from 56 to $1530 \Omega$ when $E_{\text {appl }}$ goes from 1.2 to $2.7 \mathrm{~V}$ versus $\mathrm{Li}^{+} / \mathrm{Li}$. Analogous trend is observed for $R_{\mathrm{Li}_{y} \mathrm{ITO}}(115$ and $800 \mathrm{k} \Omega$ at 1.2 and $2.7 \mathrm{~V}$ versus $\mathrm{Li}^{+} / \mathrm{Li}$, resp.) when the larger semicircle at lower frequencies is analyzed. These findings indicate that the process of simultaneous lithium and electrons uptake in n-type ITO $\mathrm{Li}_{y} \mathrm{Sn}_{x} \mathrm{In}_{2-x} \mathrm{O}_{3}$ (see (2)) polarized cathodically at $1.2 \mathrm{~V}$ versus $\mathrm{Li}^{+} / \mathrm{Li}$ brings about the general increase of both electronic and ionic conductivity at both electrode/electrolyte interface and through the lithiated layer of ITO.

The solid state reduction of $\mathrm{Li}_{y} \mathrm{Sn}_{x} \mathrm{In}_{2-x} \mathrm{O}_{3}$ into $\mathrm{Li}_{y+z} \mathrm{Sn}_{x} \mathrm{In}_{2-x} \mathrm{O}_{3}$ corresponds to a process of electrochemical $n$-doping with the formation of an accumulation layer which improves the surface confined process of ionic charge transfer at the electrode/electrolyte interface. The existence of an accumulation layer in $\mathrm{Li}_{y+z} \mathrm{Sn}_{x} \mathrm{In}_{2-x} \mathrm{O}_{3}$ induces also a relative increase of the $C_{\mathrm{DL}}$ contribution in the capacitive term of high frequency (Figure $4(\mathrm{a})$ ) with respect to the situation of anodic polarization of $\mathrm{Li}_{y} \mathrm{Sn}_{x} \mathrm{In}_{2-x} \mathrm{O}_{3}$ at $2.7 \mathrm{~V}$ versus $\mathrm{Li}^{+} / \mathrm{Li}$ in which the $\mathrm{n}$-type semiconducting electrode is in a depleted state [33]. The resistive term $R_{\mathrm{Li}_{y} \mathrm{ITO}}$ associated with the process of charge transfer through the layer is assumed to be inversely proportional to the number of mobile charge carriers (both ionic and electronic), which are present in the layer. This accounts for the decrease of $R_{\mathrm{Li}_{\mathrm{y}} \mathrm{ITO}}$ in passing from 2.7 to $1.2 \mathrm{~V}$ versus $\mathrm{Li}^{+} / \mathrm{Li}$ since the number of mobile charge carriers of both types of nature increases within lithiated ITO upon occurrence of the solid state reduction reported in (2).

\subsection{Electrochemical Behavior of CS and RDS $\mathrm{NiO}_{x}$ Coatings} on ITO. After coating a noncycled ITO substrate, that is, a nonlithiated ITO (Figures 1 and 4), with a $\mathrm{NiO}_{x}$ film deposited via conventional sintering of $50 \mathrm{~nm}$ diameter $\mathrm{NiO}_{x}$ nanoparticles (vide supra), the voltammogram of the resulting system displays the typical redox processes of the $\mathrm{NiO}_{x}$ coating, that is, broad oxidation in the interval 2.75$3.75 \mathrm{~V}$ versus $\mathrm{Li}^{+} / \mathrm{Li}$ (Figure 5), and lithium ions intercalation in the potential range $1-2.5 \mathrm{~V}$ versus $\mathrm{Li}^{+} / \mathrm{Li}$ during the first cycle (not shown) [5]. Continuous cycling in the range $1-4 \mathrm{~V}$ versus $\mathrm{Li}^{+} / \mathrm{Li}$ leads to the reproduction of the electrochemical behavior of $\mathrm{Li}_{y}$-ITO with the loss of any electrochemical feature that is characteristic of $\mathrm{NiO}_{x}$ [6]. This might indicate that either the $\mathrm{NiO}_{x}$ coating detaches during electrochemical cycling or lithiated ITO loses its capability of generating holes in the $\mathrm{NiO}_{x}$ coating when it is anodically polarized. Since ITO substrate participates in reduction processes and modifies irreversibly its transport properties when the applied potential is comprised in the range $1.0 \leq E_{\text {appl }} \leq 2.6{\mathrm{~V} \text { versus } \mathrm{Li}^{+} / \mathrm{Li}}$ (Figure 1), we will have to consider only the electrochemical oxidation of CS and $\mathrm{RDS} \mathrm{NiO}_{x}$ coatings on ITO.

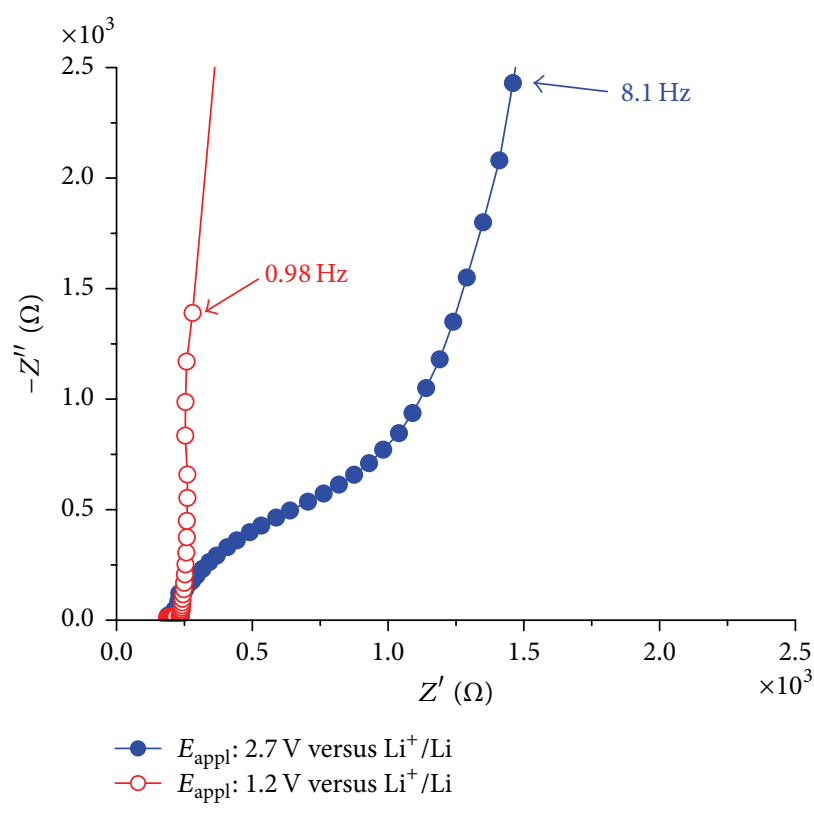

(a)

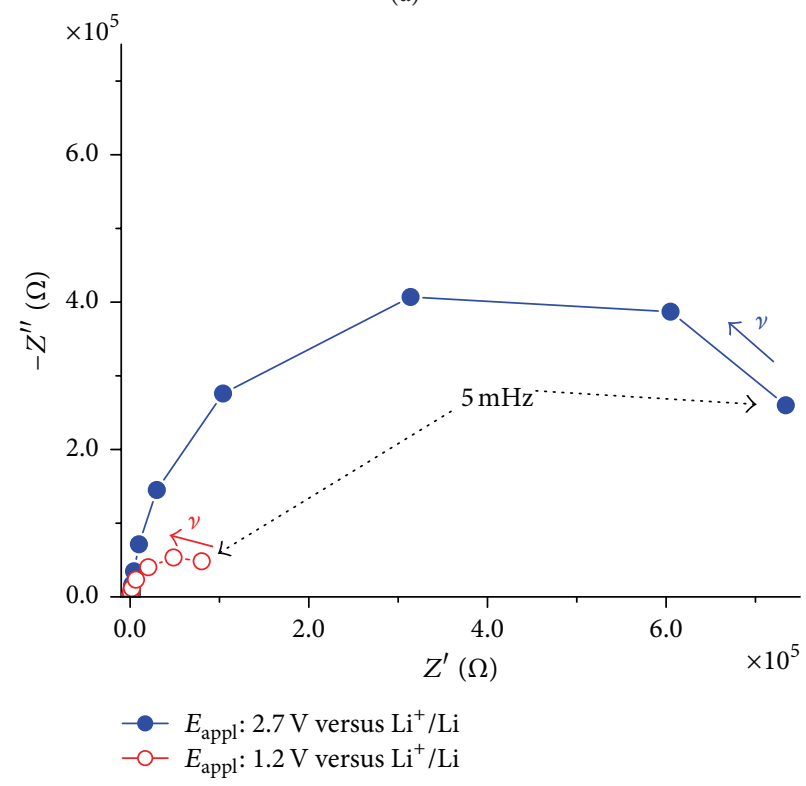

(b)

FIgURE 4: Nyquist plots in the high (a) and low (b) frequency range for lithiated ITO at $2.7 \mathrm{~V}$ versus $\mathrm{Li}^{+} / \mathrm{Li}$ and $1.2 \mathrm{~V}$ versus $\mathrm{Li}^{+} / \mathrm{Li}$ after stabilization of the voltammogram (see Figure 1).
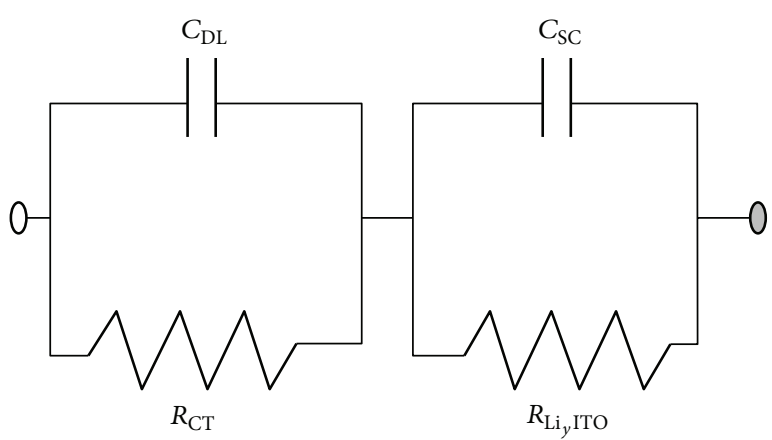

FIGURE 5: Proposed scheme of equivalent circuit for lithiated ITO $\mathrm{Li}_{y+z} \mathrm{Sn}_{x} \mathrm{In}_{2-x} \mathrm{O}_{3}$ polarized at 1.2 and $2.7 \mathrm{~V}$ versus $\mathrm{Li}^{+} / \mathrm{Li}$. 


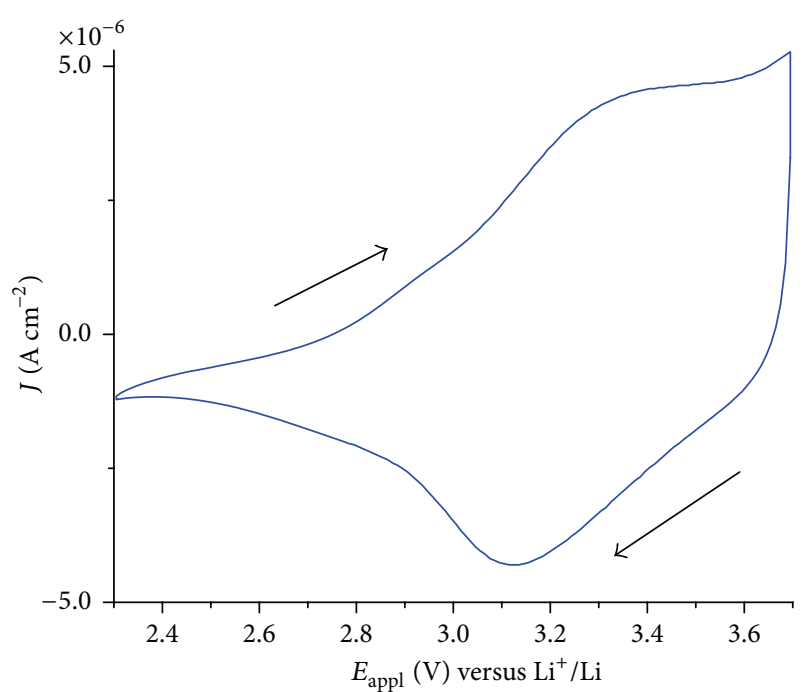

Figure 6: Cyclic voltammograms of $\mathrm{CS} \mathrm{NiO}_{x}(l=0.3 \mu \mathrm{m})$ spraydeposited onto ITO. Counter electrode: $\mathrm{Li}$; reference redox couple: $\mathrm{Li}^{+} / \mathrm{Li}$; scan rate: $5 \mathrm{mV} \mathrm{s}^{-1}$. Electrolyte composition as in Figure 1. Arrows indicate the verse of potential scan.

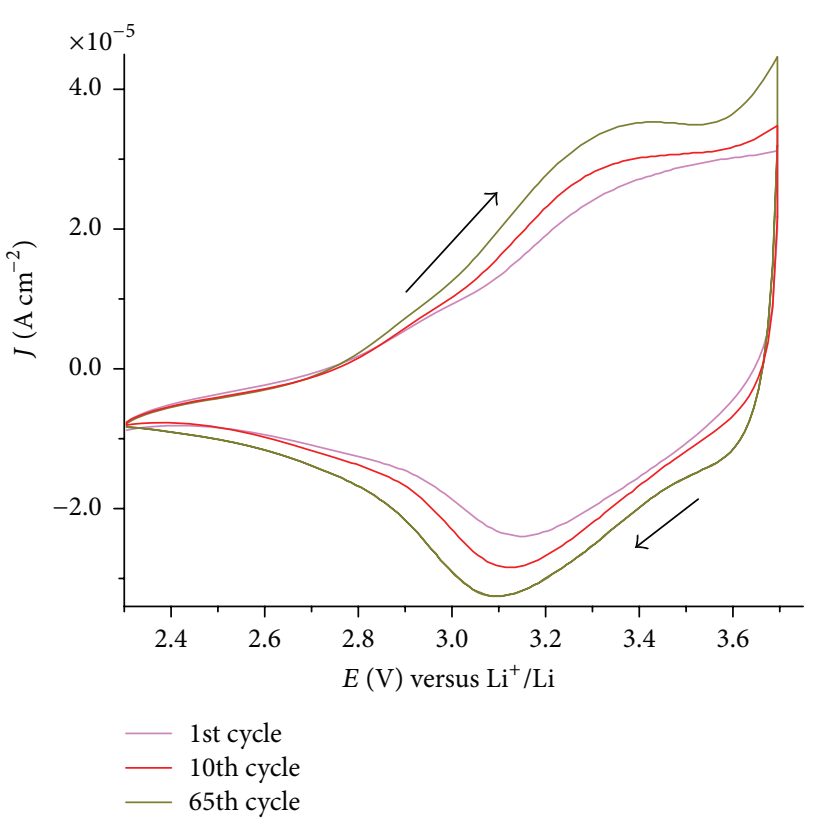

Figure 7: Cyclic voltammograms of $\mathrm{RDS}^{\mathrm{NiO}} \mathrm{O}_{x}(l=0.3 \mu \mathrm{m})$ spraydeposited onto ITO. Counter electrode: $\mathrm{Li}$; reference redox couple: $\mathrm{Li}^{+} / \mathrm{Li}$; scan rate: $5 \mathrm{mV} \mathrm{s}^{-1}$. Electrolyte composition as in Figure 1. The activation of the process of $\mathrm{NiO}_{x}$ oxidation is proven by the increase of the current density upon repetitive cycling. No further increase of the exchange current is observed after 70 cycles. Arrows indicate the verse of potential scan.

In fact, only $\mathrm{NiO}_{x}$ oxidation process can be analyzed correctly when ITO is the substrate to avoid the interferences of ITO due to its electroactivity in the potential regime of oxide reduction. CS and $\mathrm{RDS} \mathrm{NiO}_{x}$ oxidize in the range $2.7 \leq$ $E_{\text {appl }} \leq 3.7 \mathrm{~V}$ versus $\mathrm{Li}^{+} / \mathrm{Li}$ (Figures 5 and 6 ). This process of oxidation occurs in a quasi-reversible fashion for both types of samples. Different to CS (Figure 5), in the case of the RDS sample, a phenomenon of electrochemical activation of $\mathrm{NiO}_{x}$ consisting in the increase of the current density of oxidation upon continuous cycling is quite evident. The voltammogram of $\mathrm{RDS} \mathrm{NiO}_{x}$ stabilizes fully after about 100 voltammetry cycles in the potential range $2.3-3.7 \mathrm{~V}$ versus $\mathrm{Li}^{+} / \mathrm{Li}$ (Figure 7). To account for such differences we consider now the two main plausible mechanisms of charge compensation that might intervene during the electrochemical oxidation of $\mathrm{NiO}_{x}$ in nonaqueous electrolyte: (i) the uptake of anions ( $\mathrm{X}^{-}$ in (3)) from the electrolyte which, upon $\mathrm{NiO}_{x}$ oxidation, will be localized either on the surface of the metal oxide and/or within its structure [34] according to

$$
\begin{aligned}
& \mathrm{Ni}^{(\mathrm{II})}{ }_{1-y} \mathrm{Ni}^{(\mathrm{III})}{ }_{y} \mathrm{O}_{1+y / 2}+m \mathrm{X}^{-} \\
& \quad \longrightarrow \mathrm{Ni}^{(\mathrm{II})}{ }_{1-y-m} \mathrm{Ni}^{(\mathrm{III})}{ }_{y+m} \mathrm{O}_{1+y / 2}(\mathrm{X})_{m}+m \mathrm{e}^{-}
\end{aligned}
$$

and (ii) the release of hydrogen cations from the surface of nickel oxide if the latter is formed by a mixture of oxide and hydroxide on its surface (surface hydration of pristine $\mathrm{NiO}_{x}$ ) [35] according to

$$
\mathrm{NiO}_{x}(\mathrm{OH})_{m} \longrightarrow \mathrm{NiO}_{x+1}(\mathrm{OH})_{m-1}+\mathrm{e}^{-}+\mathrm{H}^{+}
$$

Since the mechanism of charge compensation reported in (3) implies more dramatic alterations of the host structure of $\mathrm{NiO}_{x}$ following the uptake of an anion by $\mathrm{NiO}_{x}$ with respect to surface deprotonation according to (4) [36], it is believed that the electrochemical activation of the RDS sample (Figure 6) is associated with the mechanism of Figure 4 with $\mathrm{X}^{-}$ representing the perchlorate anion $\mathrm{ClO}_{4}{ }^{-}$in the experimental conditions of Figure 6 . On the other hand, the lack of a clear phase of electrochemical activation in $\mathrm{CS} \mathrm{NiO}_{x}$ (Figure 5) is expected to be mostly a consequence of $\mathrm{NiO}_{x}(\mathrm{OH})_{m}$ surface deprotonation, which constitutes a milder process in terms of structural rearrangements for oxidized $\mathrm{NiO}_{x}$ (see (4)). A possible reason for such a difference could be related to the different mechanisms and speed of heat wave propagation during the step of sintering for CS and RDS samples, with CS procedure that does not remove completely the water adsorbed on the hydrophilic surface of nanoporous $\mathrm{NiO}_{x}$ during sintering. Anyhow, both mechanisms of (3) and (4) can take place simultaneously at a different extent for CS and RDS samples. Electroactive $\mathrm{NiO}_{x}$ film is supposed to contain nickel ions in both oxidation states +2 and +3 in CS and RDS nickel oxide. This is because the onset of $\mathrm{NiO}_{x}$ oxidation is about $2.8 \mathrm{~V}$ versus $\mathrm{Li}^{+} / \mathrm{Li}$ for both CS and RDS nickel oxide. This indicates that the pristine film of sintered $\mathrm{NiO}_{x}$ already contains a fraction of $\mathrm{Ni}^{(\mathrm{III})}$ sites since the open circuit voltage $(\mathrm{OCV})$ of the three-electrode cell 


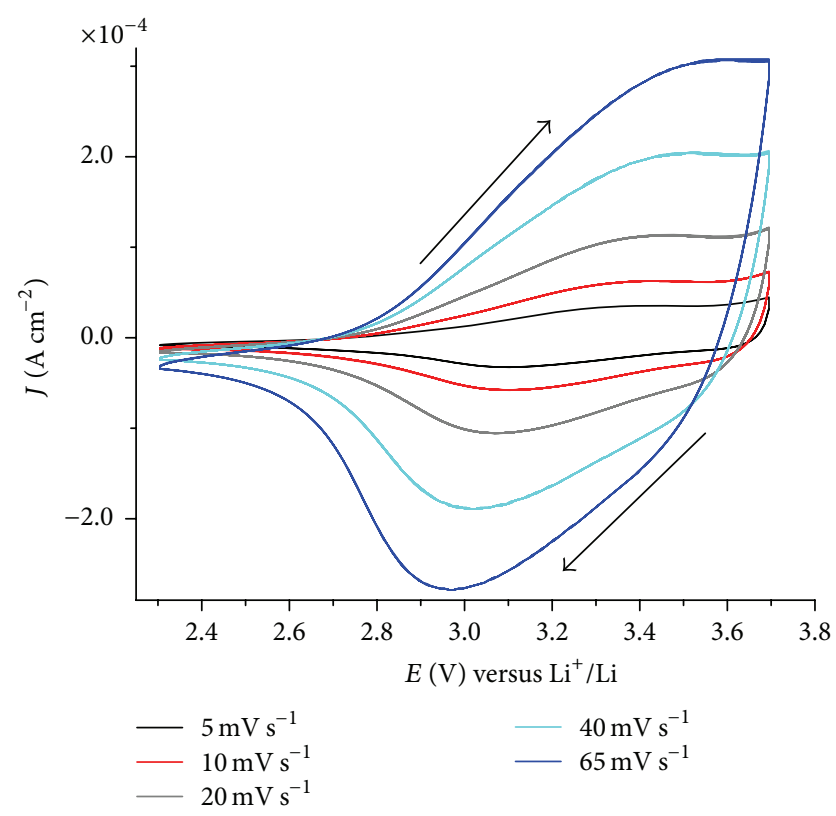

FIGURE 8: Scan rate dependence of the cyclic voltammograms of $\mathrm{RDS} \mathrm{NiO}_{x}$ spray-deposited onto ITO. Cell configuration and electrolyte composition as in Figure 1. Prior to these experiments RDS $\mathrm{NiO}$ was cycled until the completion of the activation of the oxidation process (see Figure 1). Arrows indicate the verse of potential scan.

is slightly above $3 \mathrm{~V}$ versus $\mathrm{Li}^{+} / \mathrm{Li}$ for both types of $\mathrm{NiO}$ samples, that is, a value which is higher than the onset of $\mathrm{Ni}^{(\mathrm{II})}$ site oxidation. The cyclic voltammetries of RDS and $\mathrm{CS} \mathrm{NiO}_{x}$ have been recorded at various scan rates (Figures 8 and 9).

From these profiles the better defined reduction peaks of $\mathrm{CS}$ and $\mathrm{RDS} \mathrm{NiO}$ at $2.96 \mathrm{~V}$ versus $\mathrm{Li}^{+} / \mathrm{Li}$ have been chosen for the analysis of the dependence of $\mathrm{NiO}_{x}$ voltammograms on the applied scan rate. This probe current peak corresponds to the reverse of the process(es) of (3) and (4). A linear relationship was found between peak height and scan rate for both types of oxide samples as shown in Figures 10 and 11.

Such an electrochemical behavior corresponds to the occurrence of a surface confined redox process [37], the rate of which does not depend on the diffusion of charge carriers or mass transfer processes (vide supra). This finding obtained with our CS and RDS $\mathrm{NiO}_{x}$ is consistent with the previous results presented by Boschloo and Hagfeldt who studied nickel oxide thin films prepared via a sol-gel method [8].

The impedance spectra of $\mathrm{CS} \mathrm{NiO}_{x}$ films have been recorded at $E_{\text {appl }}=2.80$ and $3.55 \mathrm{~V}$ versus $\mathrm{Li}^{+} / \mathrm{Li}$ (Figure 12). At these potential values, $\mathrm{CS} \mathrm{NiO}_{x}$ is at the onset of its oxidation and in the fully oxidized state, respectively (Figure 6). The Nyquist plot of $\mathrm{NiO}_{x}$ when $E_{\text {appl }}=2.80 \mathrm{~V}$ versus $\mathrm{Li}^{+} / \mathrm{Li}$ (three-electrode cell configuration with the sequence of (a)) shows a clearly defined semicircle at higher frequencies (Figure 12, inset), which is intersected by a second larger illdefined and uncompleted semicircle in correspondence to the stimulus frequency of $970 \mathrm{~Hz}$ (Figure 12, inset). At the lowest frequencies $(\nu \leq 40 \mathrm{mHz})$ a new regime of transport starts for

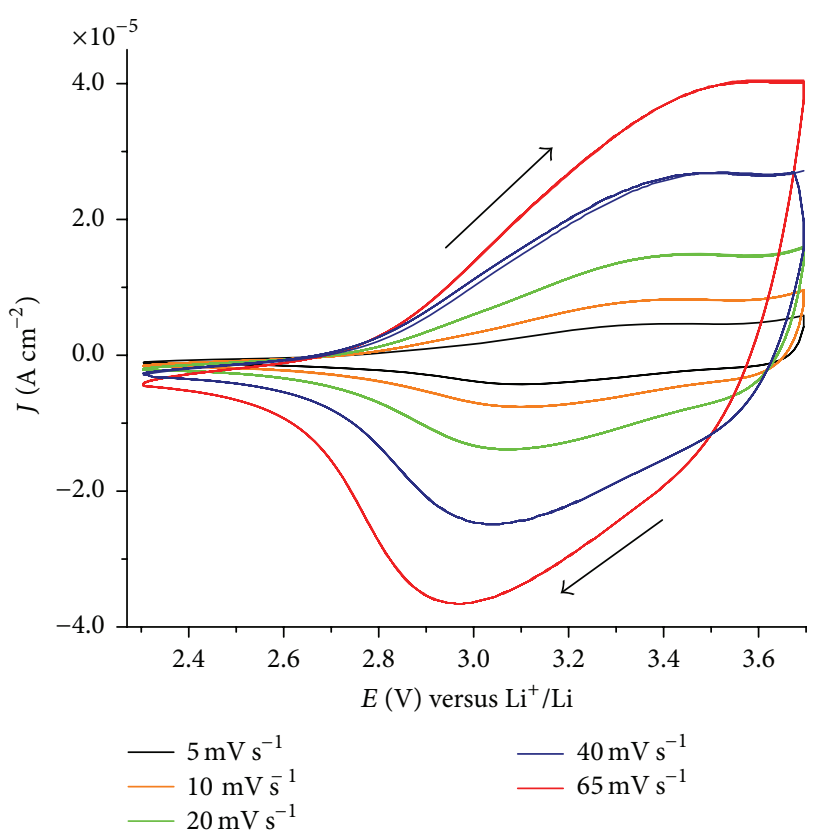

FIgURE 9: Cyclic voltammograms of $\mathrm{CS} \mathrm{NiO}_{x}(l=0.3 \mu \mathrm{m})$ spraydeposited onto ITO. Voltammograms have been recorded at several scan rates. Counter electrode: $\mathrm{Li}$; reference redox couple: $\mathrm{Li}^{+} / \mathrm{Li}$; scan rate: $5 \mathrm{mV} \mathrm{s}^{-1}$. Electrolyte composition as in Figure 1. Arrows indicate the verse of potential scan.

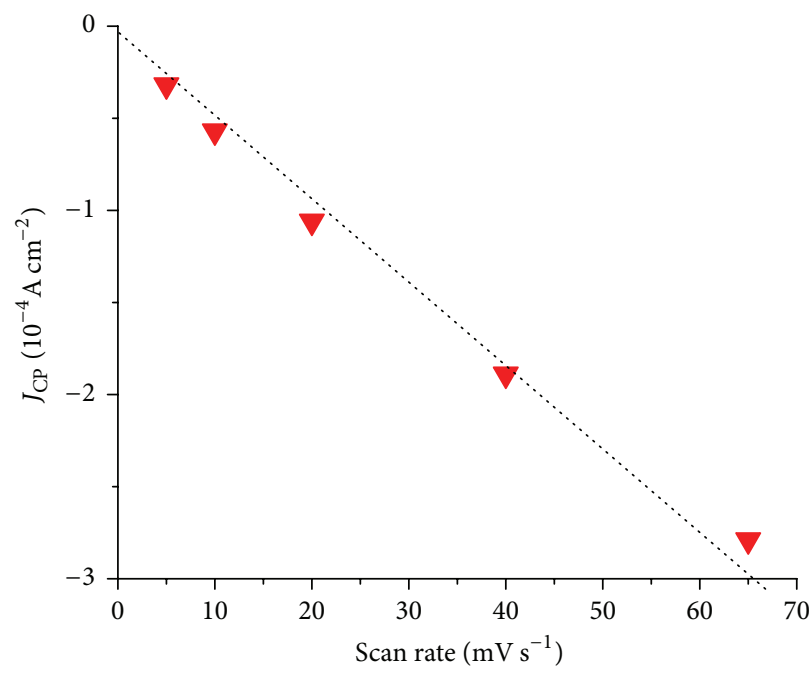

FIGURE 10: Scan rate dependence of the cathodic peak positioned between 2.9 and $3.1 \mathrm{~V}$ versus $\mathrm{Li}^{+} / \mathrm{Li}$ for the sample of RDS $\mathrm{NiO}$ $(l=0.3 \mu \mathrm{m})$ spray-deposited onto ITO. Cell configuration and electrolyte composition as in Figure 1. Data extracted from Figure 6.

$\mathrm{CS} \mathrm{NiO}$ p polarized at $2.80 \mathrm{~V}$ versus $\mathrm{Li}^{+} / \mathrm{Li}$ since the signal has a linear trend with the slope of approximately $45^{\circ}$. This linear trend tends to become vertical upon further decrease of the stimulus frequency (Figure 12). For this type of spectrum we propose tentatively the scheme of equivalent electrical circuit in Figure 13. 


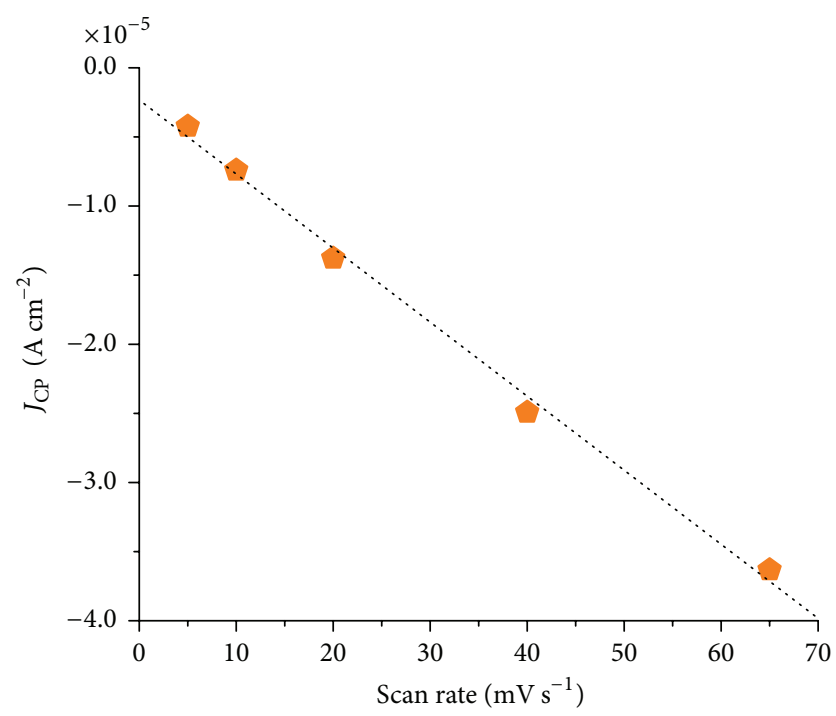

FIGURE 11: Scan rate dependence of the cathodic peak positioned at around $3.1 \mathrm{~V}$ versus $\mathrm{Li}^{+} / \mathrm{Li}$ for the sample of CS NiO $(l=0.3 \mu \mathrm{m})$ spray-deposited onto ITO. Cell configuration and electrolyte composition as in Figure 1. Data extracted from Figure 7.

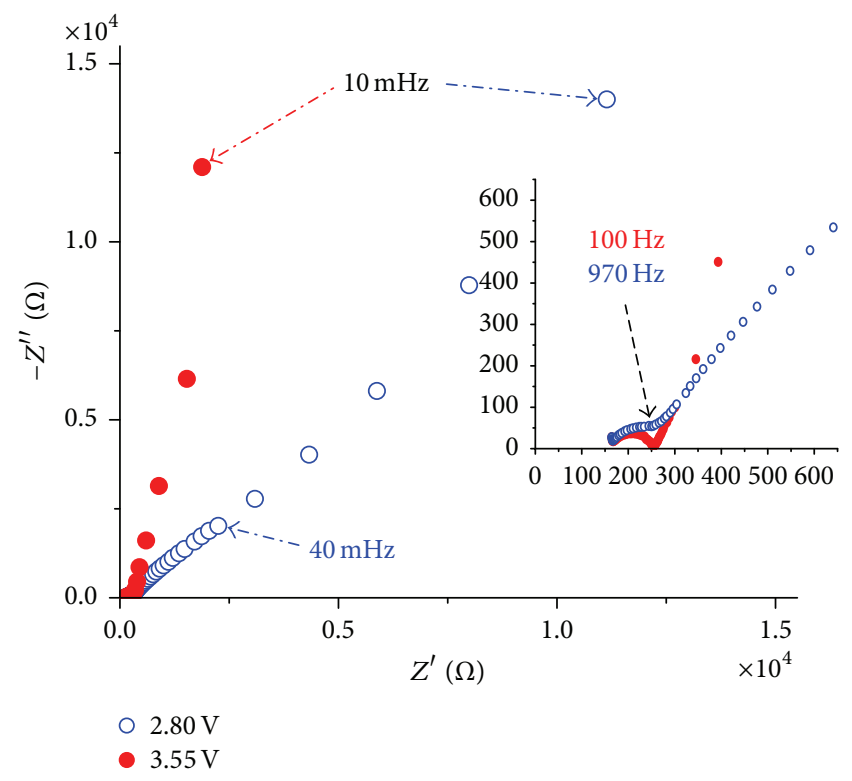

FIGURE 12: Electrochemical impedance spectra of $\mathrm{NiO}_{x}$ sintered via CS at different applied potentials $\left(2.8\right.$ and $3.55 \mathrm{~V}$ versus $\mathrm{Li}^{+} / \mathrm{Li}$ ) when film thickness is $l=0.3 \mu \mathrm{m}$. In the larger picture $40 \mathrm{mHz}$ marks the onset of the diffusive regime in $\mathrm{NiO}_{x}$ when polarized at $2.8 \mathrm{~V}$. In the inset the specified frequencies refer to the point of closure of the high-frequency semicircles. For cell configuration and electrolyte used, see Figure 1.

In the scheme of Figure 13 the symbol $R_{\text {bulk }}$ is related to the electrical transport through the mesoporous film of $\mathrm{CS} \mathrm{NiO}_{x}$ and it is considered to be a term originated from mixed conduction, that is, both ionic and electronic, within the metal oxide layer. $Z_{W}$ is the Warburg impedance associated with the diffusional motion of the various types

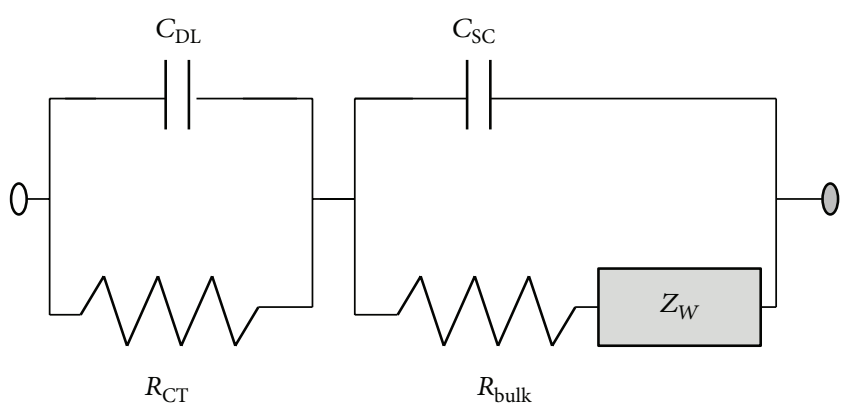

Figure 13: Proposed scheme of equivalent circuit for CS $\mathrm{NiO}_{x}$ polarized at $2.8 \mathrm{~V}$ versus $\mathrm{Li}^{+} / \mathrm{Li}$.

of charge carriers [27] present in the $\mathrm{CS} \mathrm{NiO}_{x}$ at the amount determined by the potential of the onset of its oxidation. The Warburg element $Z_{W}$ of $\mathrm{CS} \mathrm{NiO}_{x}$ sintered from oxide nanoparticles should actually comprise a transmission line $[38,39]$ that takes into account the diffusive phenomena through electrically connected particles at the basis of the charge transport within the $\mathrm{NiO}_{x}$ film. This assumption made by Bisquert for photoactive metal oxide electrodes of DSCs appears reasonable for the CS and $\mathrm{RDS} \mathrm{NiO}_{x}$ here considered since these thin layers are constituted by an agglomerate of sintered nanoparticles with average diameter $40 \mathrm{~nm}$, which build up a mesoporous irregular oxide layer with high surface area upon sintering (Figure 14).

When $\mathrm{CS} \mathrm{NiO}_{x}$ gets fully oxidized at $E_{\text {appl }}=3.55 \mathrm{~V}$ versus $\mathrm{Li}^{+} / \mathrm{Li}$, at the highest frequencies of stimulus the Nyquist plot is characterized by a clearly defined semicircle that closes at $\nu=100 \mathrm{~Hz}$ (Figure 12, inset). This is followed by a linear signal with initial slope larger than $45^{\circ}$ and becomes quasi vertical when the frequency is in the order of $10^{-2} \mathrm{~Hz}$ (Figure 12). This profile could be conveniently interpreted by the equivalent circuit presented by Passerini and Scrosati for nickel oxide [27], who considered a Randles module connected in series with a limiting capacitance $C_{L}$ (Figure 15). The latter parameter is associated with the occurrence of the finite thickness effect and confirms the existence of a blocking boundary in the system which is represented by the ITO substrate [30].

From the comparison of the EIS profiles of CS $\mathrm{NiO}_{x}$ it is evident that the polarization of $\mathrm{CS} \mathrm{NiO}_{x}$ electrode mainly affects $Z_{W}$ term that accounts for the origin of the signal after the completion of the first semicircle. The increase of the applied potential at $3.55 \mathrm{~V}$ versus $\mathrm{Li}^{+} / \mathrm{Li}$ leads to the oxidation process reported in (4) and eventually (3) for CS sample. The consequent increase of the number of $\mathrm{Ni}^{(\text {III) }}$ sites within the oxide film implies an increase of the electronic conductivity in it since $\mathrm{Ni}^{(\mathrm{III})}$ sites allow the displacement of electronic holes through the structure of the oxide [1].

The impedance spectra of $\mathrm{RDS} \mathrm{NiO}_{x}$ films have been recorded at $E_{\text {appl }}=2.3,2.8$, and $3.5 \mathrm{~V}$ versus $\mathrm{Li}^{+} / \mathrm{Li}$ (Figure 16). At these three potentials of polarization, RDS $\mathrm{NiO}_{x}$ is in the uncharged state, at the onset of its oxidation, and in the fully oxidized state, respectively (Figure 7). 


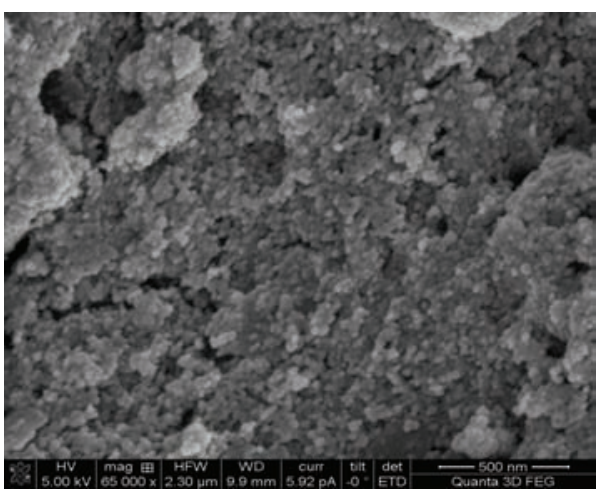

(a)

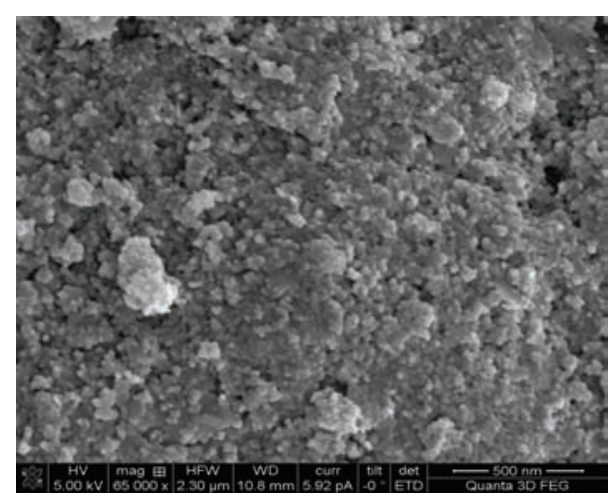

(b)

FIGURE 14: SEM image showing the surface morphology of ((a), left) RDS and ((b), right) CS NiO layer $(l=2-3 \mu \mathrm{m})$ deposited onto ITO via sintering of nanoparticles with average diameter of $40 \mathrm{~nm}$.

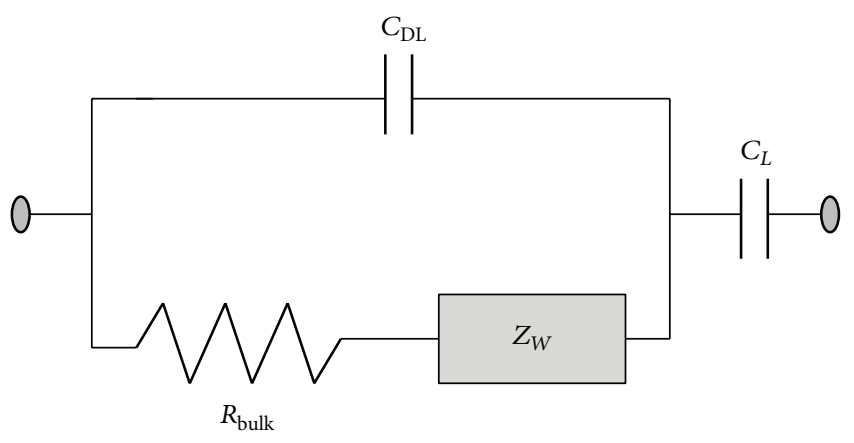

FIGURE 15: Proposed scheme of equivalent circuit for CS $\mathrm{NiO}_{x}$ polarized at $3.55 \mathrm{~V}$ versus $\mathrm{Li}^{+} / \mathrm{Li}$.

The EIS profiles of RDS $\mathrm{NiO}_{x}$ at the polarization values of 2.8 and $3.5 \mathrm{~V}$ versus $\mathrm{Li}^{+} / \mathrm{Li}$ strongly resemble the ones of CS $\mathrm{NiO}_{x}$ at the same polarization values (Figure 12). In that respect we can adopt the same considerations made in the analysis of the EIS response of CS and RDS nickel oxide (Figures 13 and 15). As far as the EI spectrum of uncharged $\mathrm{RDS} \mathrm{NiO}_{x}$ at $2.3 \mathrm{~V}$ versus $\mathrm{Li}^{+} / \mathrm{Li}$ is concerned, we observed that high-frequency semicircle (Figure 16(a), black square profile) is associated with the capacitance built up by charge separation at the $\mathrm{RDS} \mathrm{NiO}_{x}$ /electrolyte interface (double layer capacitance, $C_{\mathrm{DL}}$ ), which is connected in parallel with the charge transfer resistance $\left(R_{\mathrm{CT}}\right)$ of ionic insertion/extraction through the same interface. The electrical parameters associated with the uncompleted semicircle observed at the lower frequencies (Figure 16(b), black square profile) are associated with the capacitance of the uncharged RDS $\mathrm{NiO}_{x}$ (capacitance of space charge layer, $C_{\mathrm{SC}}$ ) connected in parallel with the resistance of charge transport $\left(R_{\mathrm{RDS} \mathrm{NiO}_{x}}\right)$ through the same layer (Figure 17). It is clear how the RDS system in its uncharged state presents a very large semicircle of low frequency with respect to the oxidized states, which corresponds to the through-layer conduction. This is because of the relative scarcity of charge carriers in the metal oxide at this state of polarization in comparison to the states with a larger amount of $\mathrm{Ni}^{(\mathrm{III})}$ sites $\left(E_{\text {appl }}=2.8\right.$ and $3.5 \mathrm{~V}$ versus $\left.\mathrm{Li}^{+} / \mathrm{Li}\right)$.

3.3. Electrochemical and Photoelectrochemical Properties of ERY-Sensitized CS and RDS $\mathrm{NiO}_{x}$. The porous nature of the $\mathrm{NiO}_{x}$ coatings sintered via CS and RDS procedures (Figure 14) and their transparency render the efficacious sensitization of the oxide with a visible light absorber possible. In the present work erythrosine (ERY) B has been considered as dye sensitizer because of the matching of its frontier energy levels with the band edges of $\mathrm{p}$-type $\mathrm{NiO}_{x}$ for DSCs purposes $[13,21]$. The dye sensitization of sintered $\mathrm{NiO}_{x}$ sample with ERY colorant generally leads to a decrease of the dark current densities with respect to the corresponding voltammetry curves of bare nickel oxide samples with ERY behaving as an agent of surface passivation towards $\mathrm{NiO}_{x}$ oxidation [40]. The cyclic voltammetries of ERY colored $\mathrm{NiO}_{x}$ are presented in Figures 18 and 19 for RDS and CS samples, respectively, when various scan rates were adopted.

In the ERY colored state, $\mathrm{RDS} \mathrm{NiO}_{x}$ undergoes a phenomenon of electrochemical activation (Figure 18(a)) similar to what was verified with the bare state (Figure 7 ). This is indicative of the same nature of the oxidative process for both ERY-sensitized and bare RDS $\mathrm{NiO}_{x}$. The oxidation of RDS $\mathrm{NiO}_{x}$ occurs prevalently according to the mechanism of (3) regardless of the state of its surface, that is, whether sensitized or not. This implies that ERY-based electrochemical processes are not introduced in the dark voltammogram of ERYsensitized RDS $\mathrm{NiO}_{x}$ deposited on ITO substrates when the range of $\mathrm{RDS} \mathrm{NiO}_{x}$ oxidation potentials is explored (Figure 8). Same considerations hold when the voltammetries of $\mathrm{CS} \mathrm{NiO}$ are analyzed (Figure 19). Under these circumstances chemisorbed ERY behaves as an electrochemically inert layer with no direct involvement in any of the observed Faradic processes (case of nonelectroactive dye sensitizer in the immobilized state) [41]. The height of the broad current peak generated with the oxidation of ERY-sensitized RDS and CS $\mathrm{NiO}_{x}$ follows a linear trend with the scan rate (not shown). This means that also the oxidation of the ERY-sensitized $\mathrm{NiO}_{x}$ samples constitutes a redox process which is surface confined 


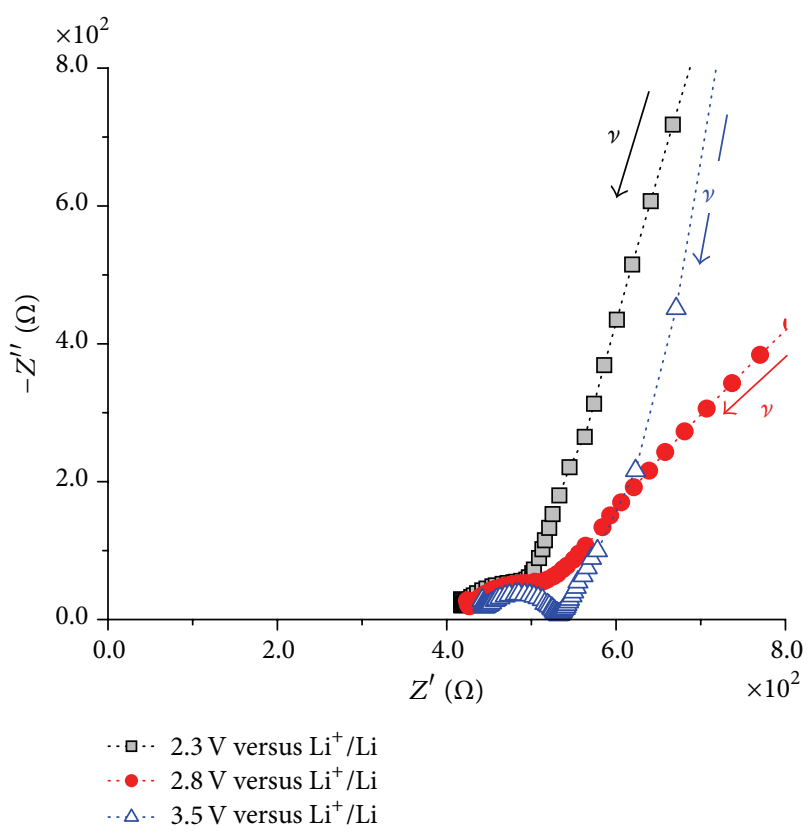

(a)

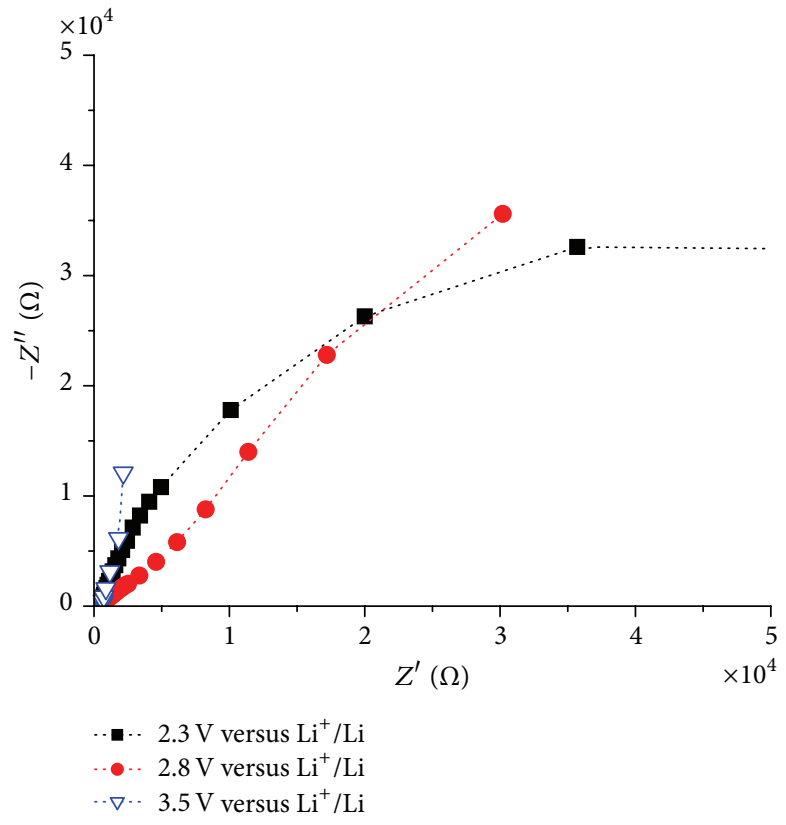

(b)

Figure 16: (a) High- and (b) low-frequency electrochemical impedance spectra of $\mathrm{RDS}_{\mathrm{NiO}}(l=0.3 \mu \mathrm{m})$ spray-deposited onto ITO. Impedance spectra were recorded at different applied potentials $\left(E_{\text {appl }}\right)$. The selected values of $E_{\text {appl }}$ are related to the nature of the $\mathrm{NiO} x$ layer, in the pristine uncharged state $\left(E_{\text {appl }}=2.3 \mathrm{~V}\right.$ versus $\left.\mathrm{Li}^{+} / \mathrm{Li}\right)$, in the partially oxidized state $\left(E_{\text {appl }}=2.8 \mathrm{~V} \mathrm{versus} \mathrm{Li}^{+} / \mathrm{Li}\right)$, and in the fully oxidized state $\left(E_{\text {appl }}=3.5 \mathrm{~V}\right.$ versus $\left.\mathrm{Li}^{+} / \mathrm{Li}\right)$. For electrolyte and cell configuration used, see Figure 1 . In the upper plot the arrows indicate the direction of increase for the frequency of polarization.

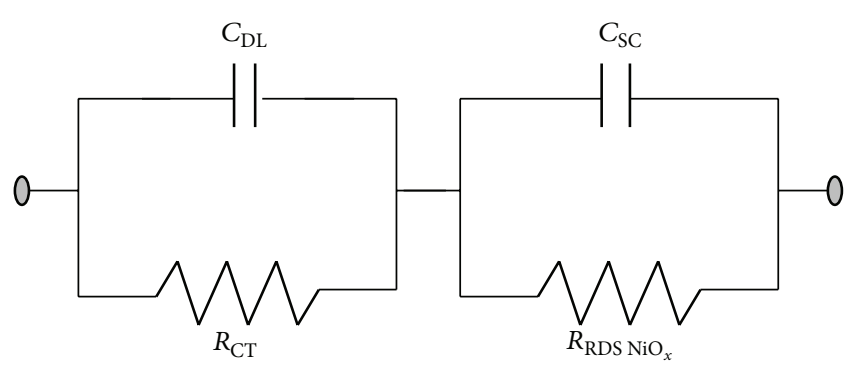

Figure 17: Proposed scheme of equivalent circuit for $\mathrm{RDS} \mathrm{NiO}_{x}$ polarized at $2.3 \mathrm{~V}$ versus $\mathrm{Li}^{+} / \mathrm{Li}$.

[37] for both CS and RDS types. Therefore, $\mathrm{NiO}_{x}$ in the ERYsensitized state represents the sole actual redox species in the applied potential range $2.4-3.7 \mathrm{~V}$ versus $\mathrm{Li}^{+} / \mathrm{Li}$ when cycling in dark conditions. This is in full agreement with the findings relative to the electrochemical behavior of CS and RDS $\mathrm{NiO}_{x}$ samples when they are cycled in the uncolored bare state (Figures 10 and 11).

The cyclic voltammetries of ERY-sensitized RDS and CS $\mathrm{NiO}_{x}$ have been recorded also under illumination with white light (Figures 20 and 21) at different scan rates to study the nature of the possible photoeffects generated by the presence of the colorant chemisorbed on mesoporous $\mathrm{NiO}_{x}$. When compared to the corresponding dark profiles (Figures 22 and 23), it is noted that the illumination of the dye-sensitised CS and RDS metal oxide samples with white light produces two main effects: (i) an increase of the oxidation current density and (ii) the negative shift of the current baseline with respect to the dark profiles in the potential region where no redox processes occur in the dark state (Figures 22 and 23). These facts can be explained in terms of photogeneration of positive charge carriers [42] in dye-sensitised nickel oxide of both types when visible light is absorbed by the ERY monolayer (photoconductive effect) $[9,21]$. The observed photoconductive effects have to be ascribed exclusively to the presence of ERY and not to the film of $\mathrm{NiO}_{x}$ since it has been previously demonstrated that irradiation of bare $\mathrm{NiO}_{x}$ does not produce any photoconductive or photoelectrochemical effect in the potential window corresponding to the dark oxidation of bare $\mathrm{NiO}_{x}[9,43]$.

Cyclic voltammetries of ERY-sensitised $\mathrm{NiO}_{x}$ of CS and RDS types have been carried out at different scan rates under white light illumination (Figures 20 and 21) to evaluate the characteristics of the photooxidation process of ERYsensitised $\mathrm{NiO}_{x}$ when in the sensitized state. The cathodic peak referring to the reverse process $\mathrm{Ni}^{(\mathrm{III})} \rightarrow \mathrm{Ni}^{(\mathrm{II})}$ (reverse of processes in (3) and/or (4)) has been chosen for scan rate analysis because of its generally better resolution with respect to the correlated broader anodic peak. Both dark and photoelectrochemical oxidation processes of ERYsensitized CS $\mathrm{NiO}_{x}$ spray-deposited onto ITO present the typical features of a surface confined redox process, with the cathodic current peaks being directly proportional to the scan rate (Figure 24). 


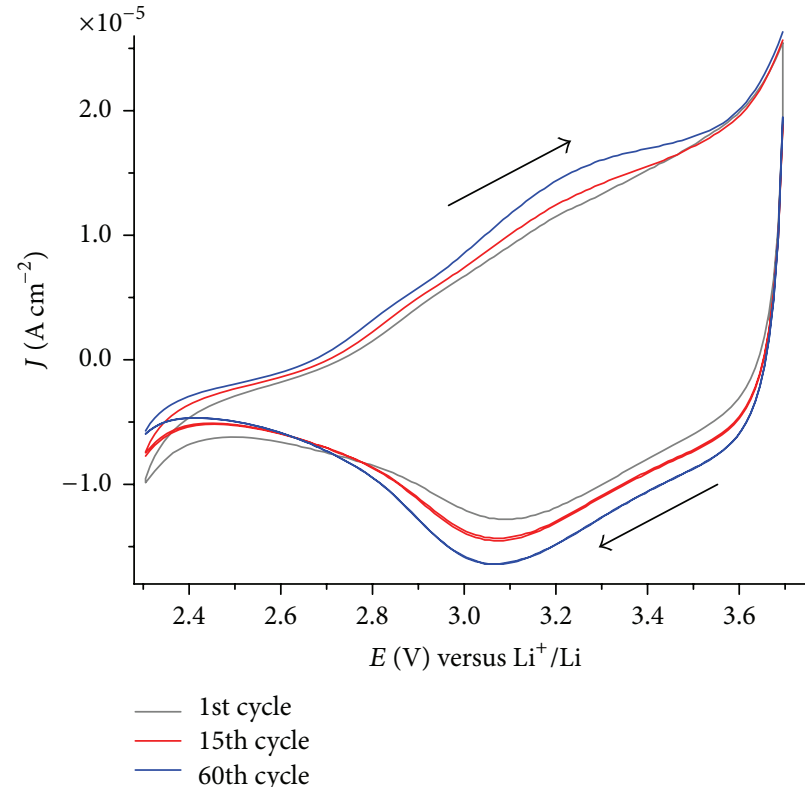

(a)

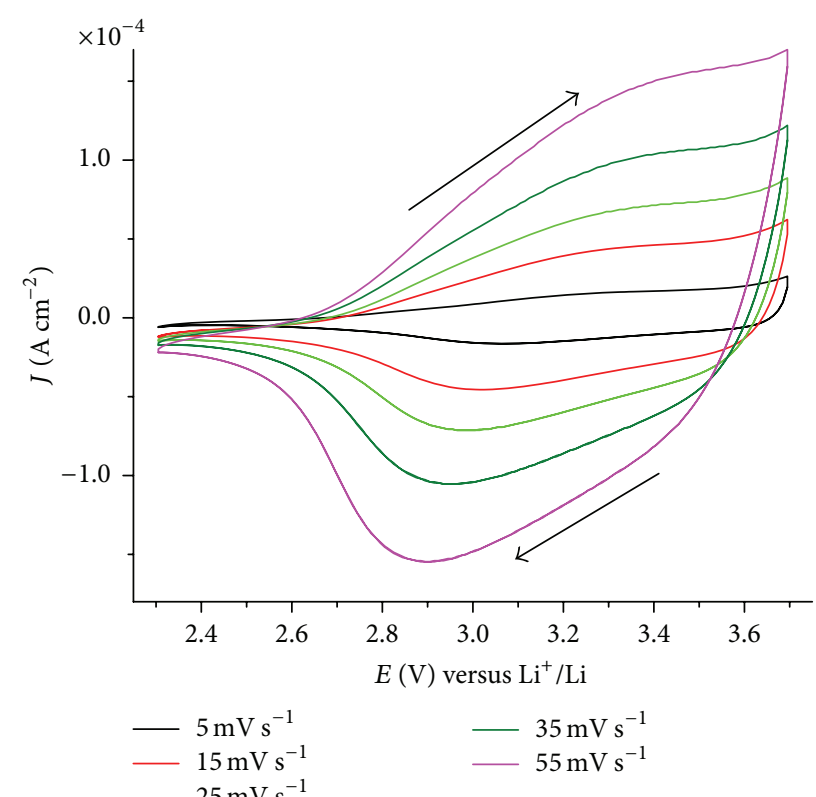

(b)

FIgURE 18: (a) Modification of the voltammogram of ERY-sensitized $\mathrm{RDS} \mathrm{NiO}_{x}$ on ITO at $5 \mathrm{mV} \mathrm{s}^{-1}$ in dark conditions upon continuous cycling (nickel oxide sample as in Figure 7). Electrolyte and cell configuration as in Figure 1. After about 60 cycles the voltammogram had a stabilized profile. Arrows indicate the verse of potential scan. (b) Cyclic voltammograms of ERY-sensitized RDS NiO spray-deposited onto ITO after stabilization of the voltammogram (a). All voltammograms have been recorded in dark conditions. Scan rates have been varied between 5 and $55 \mathrm{mV} \mathrm{s}^{-1}$. ERY-sensitized RDS NiO sample was initially cycled 80 times at $5 \mathrm{mV} \mathrm{s}^{-1}$ (a). Counter electrode: Li; reference redox couple: $\mathrm{Li}^{+} / \mathrm{Li}$. Electrolyte composition as in Figure 1. Arrows indicate the verse of potential scan.

It is supposed that the simultaneous irradiation and electrochemical polarization of ERY-sensitized CS/RDS $\mathrm{NiO}_{x}$ in the regime of oxidation lead to an additional injection of electronic charge in the film of oxidized nickel oxide according to the sequence depicted in Figure 25.

To support this hypothesis it is necessary to record in situ the transient optical spectra of ERY-sensitized CS/RDS $\mathrm{NiO}_{x}$ upon simultaneous illumination and electrochemical polarization at different scan rates. This measurement would clarify the mechanism and the kinetics of the possible photoinduced charge injection between the ERY monolayer and the $\mathrm{NiO}_{x}$ film under illumination through the detection of the variations of the spectrum of immobilized ERY [44]. In absence of a redox species in solution, the spectral features of ERY can be associated either with its transient excited state (case of Figure 25(a)) or the oxidized state (case of Figures 25(b) and 25(c)) depending on the relative rates of charge injection, electron back donation, and electrochemical hole formation in CS/RDS $\mathrm{NiO}_{x}$.

The impedance spectra of ERY-sensitized CS and RDS $\mathrm{NiO}_{x}$ films have been recorded in dark conditions at different values of applied potential (Figures 26 and 27). For ERY$\mathrm{CS} \mathrm{NiO}_{x}$ (Figure 26) the potential values here considered correspond to the three distinct states of neutral ERY-CS $\mathrm{NiO}_{x}\left(2.4 \mathrm{~V}_{\text {versus }} \mathrm{Li}^{+} / \mathrm{Li}\right.$, Figure 19$)$, of poorly oxidized ERY$\mathrm{CS} \mathrm{NiO}_{x}\left(2.6 \mathrm{~V}\right.$ versus $\mathrm{Li}^{+} / \mathrm{Li}$, Figure 19), and of fully oxidized ERY-CS $\mathrm{NiO}_{x}\left(3.6 \mathrm{~V}\right.$ versus $\mathrm{Li}^{+} / \mathrm{Li}$, Figure 19). In the case of ERY-RDS $\mathrm{NiO}_{x}$ (Figure 27) the selected values of polarization were $2.4,3.0$, and $3.6 \mathrm{~V}$ versus $\mathrm{Li}^{+} / \mathrm{Li}$ which correspond to neutral, partially oxidized, and fully oxidized ERY-RDS $\mathrm{NiO}_{x}$, respectively (Figure 18(b)).

For the analysis of the EIS profiles of ERY-sensitized CS $\mathrm{NiO}_{x}$ the model of equivalent circuit proposed in Figure 13 is considered. This model refers originally to bare CS $\mathrm{NiO}_{x}$ polarized at $2.8 \mathrm{~V}$ versus $\mathrm{Li}^{+} / \mathrm{Li}$, that is, a value at which $R_{\mathrm{CT}}$ is finite at the interface bare electrode/electrolyte. In the case of ERY-sensitized CS $\mathrm{NiO}_{x}$ the corresponding $R_{\mathrm{CT}}$ (model of Figure 13) is poorly affected by the state of polarization of the sensitized oxide. The latter statement is supported by the constancy of the amplitude of the semicircle determined at high frequencies for all the values of applied potential (Figure 26(a)). The more ample semicircle recorded in the low-frequency range is well defined and complete only at the polarization value of $2.4 \mathrm{~V}$ versus $\mathrm{Li}^{+} / \mathrm{Li}$ and is associated with bulk charge transport within ERY-sensitized CS $\mathrm{NiO}_{x}$ (corresponding electrical parameters: $R_{\text {bulk }}$ and $Z_{W}$ in Figure 13) and the charge separation within the sensitized film (corresponding electrical parameter: $C_{\mathrm{SC}}$ in Figure 13). The feature of low-frequency semicircle results to be ill defined at the largest values of polarization for which $\mathrm{CS} \mathrm{NiO}_{x}$ is either partially or fully oxidized (Figure 19). In correspondence to dark CS $\mathrm{NiO}_{x}$ oxidation in the sensitized state the ERY layer is not electroactive (Figure 20) but affects the lowfrequency range signal by modifying the distribution of charge within the ERY-sensitized film (capacitive term $C_{\mathrm{SC}}$ in Figure 13) in comparison to oxidized bare CS oxide (Figure 12, 


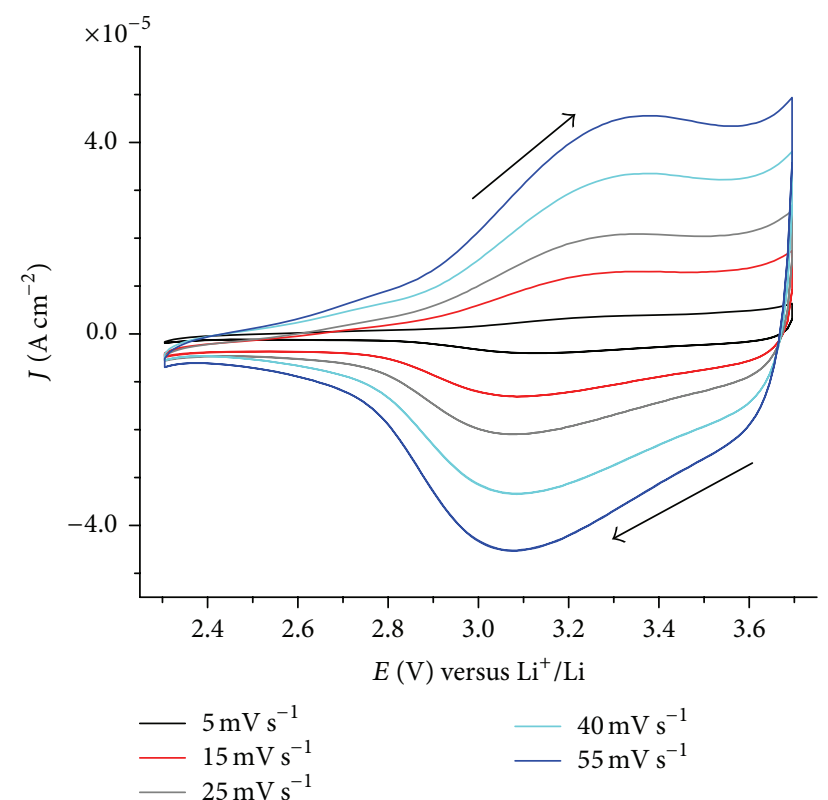

FIGURE 19: Scan rate dependence of the cyclic voltammograms of ERY-sensitized CS $\mathrm{NiO}_{x}$ spray-deposited onto ITO. All voltammograms have been recorded in dark conditions within the potential range of bare $\mathrm{CS} \mathrm{NiO}_{x}$ oxidation (Figures 6 and 9). Scan rates were varied between 5 and $55 \mathrm{mV} \mathrm{s}^{-1}$. Counter electrode: Li; reference redox couple: $\mathrm{Li}^{+} / \mathrm{Li}$. Electrolyte composition as in Figure 1. Arrows indicate the verse of potential scan. Prior to sensitization the thickness of the $\mathrm{CS} \mathrm{NiO}_{x}$ coating was $0.3 \mu \mathrm{m}$.

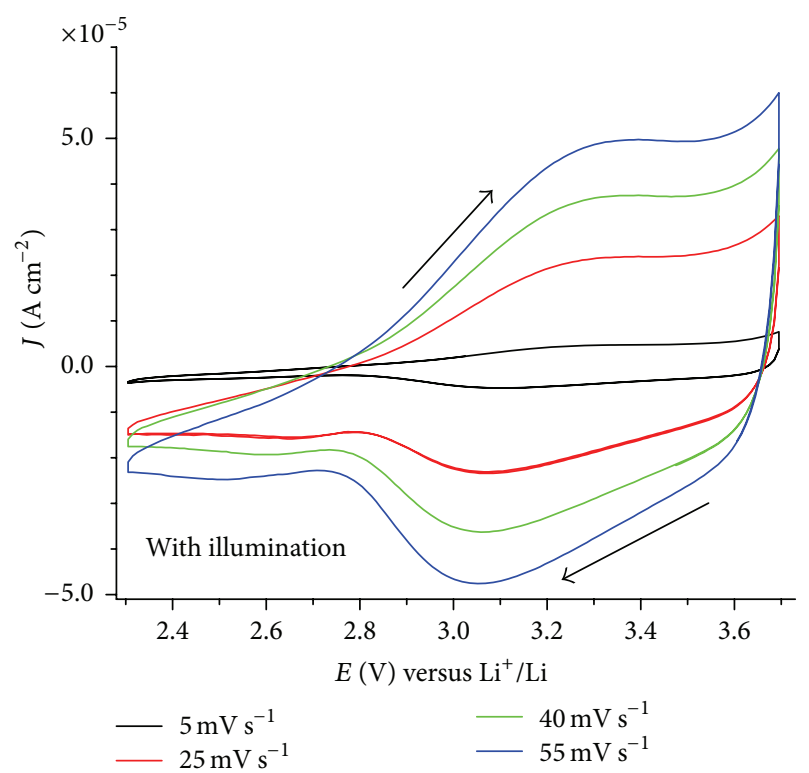

FIGURE 20: Cyclic voltammograms of ERY-sensitized CS NiO spraydeposited onto ITO. All voltammograms have been under irradiation with white light (light source: halogen lamp; $I_{\mathrm{in}}: 28.6 \mathrm{~W} \mathrm{~cm}^{-2}$ ). Scan rates have been varied between 5 and $55 \mathrm{mV} \mathrm{s}^{-1}$. The applied potential varied within the potential range of bare CS NiO oxidation in dark conditions (Figures 6 and 9). Counter electrode: Li; reference redox couple: $\mathrm{Li}^{+} / \mathrm{Li}$. Electrolyte composition as in Figure 1. Arrows indicate the verse of potential scan.

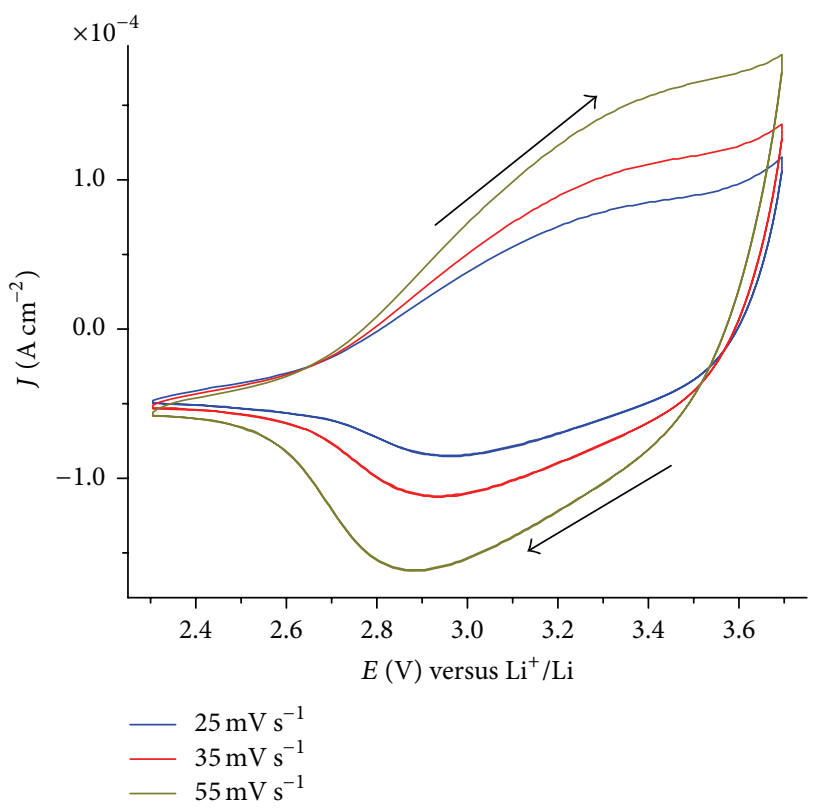

FIGURE 21: Cyclic voltammograms of ERY-sensitized RDS $\mathrm{NiO}$ spray-deposited onto ITO. All voltammograms have been under irradiation with white light (light source: halogen lamp; $I_{\text {in }}$ : $28.6 \mathrm{~W} \mathrm{~cm}^{-2}$ ). Scan rates have been varied between 25 and $55 \mathrm{mV} \mathrm{s}^{-1}$. ERY-sensitized RDS NiO sample was initially cycled 60 times at $5 \mathrm{mV} \mathrm{s}^{-1}$ in dark conditions (see Figure 18(a)). Counter electrode: $\mathrm{Li}$; reference redox couple: $\mathrm{Li}^{+} / \mathrm{Li}$. Electrolyte composition as in Figure 1. Arrows indicate the verse of potential scan.

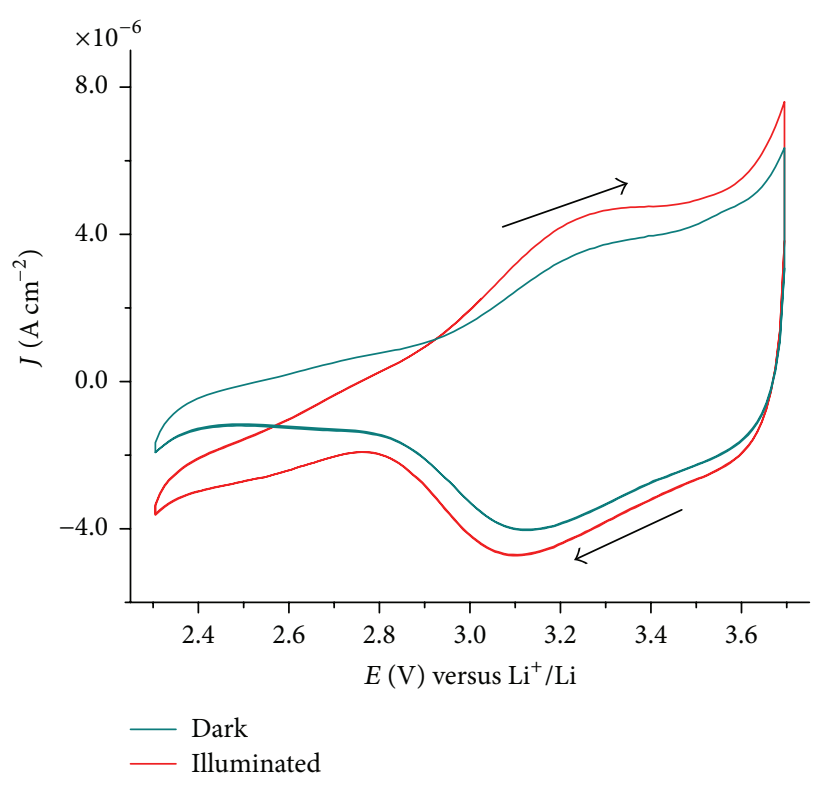

FIGURE 22: Comparison of the cyclic voltammograms of ERYsensitized CS NiO coating (thickness: $0.3 \mu \mathrm{m}$ ) in the dark and under illumination with the white light produced by a halogen lamp $\left(I_{\text {in }}\right.$ $=28.6 \mathrm{~W} \mathrm{~cm}^{-2}$ ). The applied potential was scanned at the rate of $5 \mathrm{mV} \mathrm{s}^{-1}$. Electrolyte composition as in Figure 1. Arrows indicate the direction of potential scan. Profiles have been extracted from Figure 19 (dark conditions) and Figure 20 (illuminated state). 


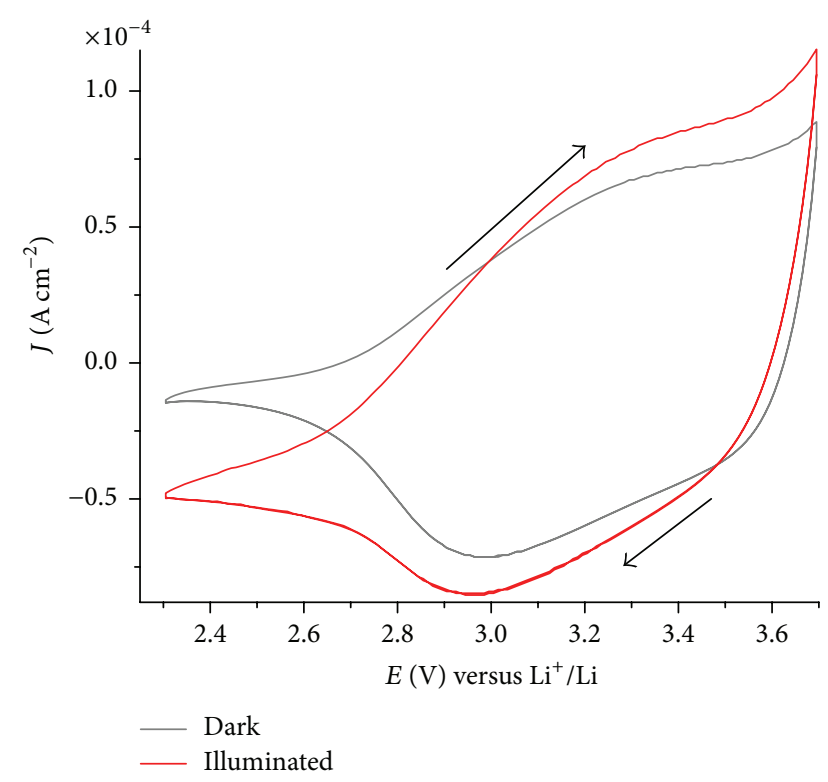

FIGURE 23: Comparison of the cyclic voltammograms of ERYsensitized RDS $\mathrm{NiO}_{x}$ spray-deposited onto ITO in dark conditions and under illumination. Both voltammograms have been recorded at the scan rate of $25 \mathrm{mV} \mathrm{s}^{-1}$. Profiles have been extracted from Figure 18(a) (dark conditions) and Figure 21 (illuminated state).

$E_{\text {appl }}=3.55 \mathrm{~V}$ versus $\left.\mathrm{Li}^{+} / \mathrm{Li}\right)$. Finite thickness effect is not observed in the impedance spectrum of ERY modified CS $\mathrm{NiO}_{x}$ (lack of the capacitive term $C_{L}$ in Figure 15). This might be indicative of the fact that ERY behaves as a trapping/blocking layer for the electrochemically injected holes of CS $\mathrm{NiO}_{x}$ in the sensitized state when $E_{\text {appl }} \geq 2.8 \mathrm{~V}$ versus $\mathrm{Li}^{+} / \mathrm{Li}$ (Figures 19 and 26) [6].

ERY-sensitized $\mathrm{RDS} \mathrm{NiO}_{x}$ presents EIS profiles (Figure 27) showing a trend analogous to the one presented by ERY-sensitized CS $\mathrm{NiO}_{x}$ (Figure 26). The high-frequency semicircle has an amplitude not dependent on the value of applied potential and is associated with a resistive term of about $150 \mathrm{Ohm}$. This term corresponds to the resistance of charge transfer through the sensitized electrode/electrolyte interface $\left(R_{\mathrm{CT}}\right.$ in Figure 13). At the lowest value of polarization $\left(E_{\text {appl }}=2.4 \mathrm{~V}\right.$ versus $\left.\mathrm{Li}^{+} / \mathrm{Li}\right)$ the impedance spectrum of ERY-sensitized $\mathrm{RDS} \mathrm{NiO}_{x}$ is characterized by an incomplete low-frequency semicircle originating from the bulk transport properties of sensitized $\mathrm{RDS} \mathrm{NiO}_{x}$ (corresponding electrical parameters: $R_{\text {bulk }}$ and $Z_{W}$ in Figure 13) and from the existence of charge separation within the sensitized RDS oxide (corresponding electrical parameter: $C_{\mathrm{SC}}$ in Figure 13). Similar to sensitized CS oxide, the sensitized version of RDS $\mathrm{NiO}_{x}$ possesses bulk transport properties and charge separation which are strongly affected by the extent of the process of electrochemical injection of holes occurring at $E_{\text {appl }} \geq$ $2.8 \mathrm{~V}$ versus $\mathrm{Li}^{+} / \mathrm{Li}$ (Figure 18), with ERY layer behaving as blocking/trapping layer for the electronic holes of oxidized $\mathrm{RDS} \mathrm{NiO}_{x}$. In the comparative analysis of the impedance

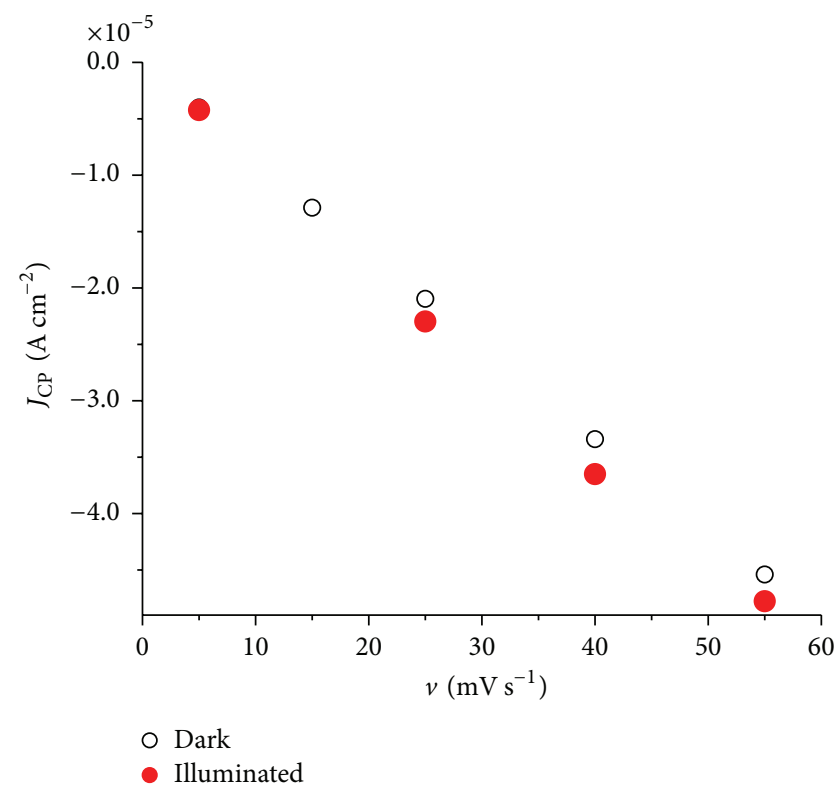

FIGURE 24: Scan rate $(v)$ dependence of the cathodic current density peak $\left(J_{\mathrm{CP}}\right)$ present in the voltammograms of ERY-sensitized CS NiO coating deposited on ITO. Data have been extracted in the dark (from Figure 19) and under illumination (from Figure 20). The potential corresponding to the cathodic current density peak varies between 3.1 and $3.2 \mathrm{~V}$ versus $\mathrm{Li}^{+} / \mathrm{Li}$, depending on the scan rate.

spectra of the ERY-sensitized samples we have deliberately neglected the interface dye/metal oxide in the model here proposed (Figure 13). The reason of that is motivated by the absence of a specific electrochemical effect produced by the ERY layer when the dark voltammograms of the two types of metal oxides in the bare and sensitized states are compared

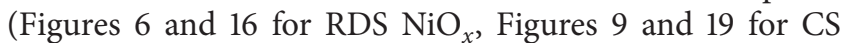
$\mathrm{NiO}_{x}$ ).

In Figure 28 we have considered the EIS signals of ERYsensitized $\mathrm{RDS} \mathrm{NiO}_{x}$ in the dark and under illumination when the potential of polarization $\left(3.0 \mathrm{~V}\right.$ versus $\left.\mathrm{Li}^{+} / \mathrm{Li}\right)$ corresponded to a state of partial oxidation for the $\mathrm{NiO}_{x}$ working electrode in dark conditions (Figure 18(b)). The high-frequency semicircle retained the same amplitude in passing from dark to illuminated state (not shown). The most remarkable differences were found in the lower frequency portion of the spectrum with the appearance of a second incomplete semicircle that decreased its amplitude in going from dark to illuminated condition (Figure 28). This feature is associated mainly with the increase of the concentration of charge carriers upon white light illumination of the ERY-sensitized oxide (Figure 25), which in turn produces a decrease of the term of bulk resistance $\left(R_{\mathrm{RDS} \mathrm{NiO}_{x}}\right.$ in Figure 17) when $\mathrm{NiO}_{x}$ is sensitized. Therefore, the photoinjection induced by the presence of ERY produces mainly the alteration of the bulk transport properties of ERY RDS $\mathrm{NiO}_{x}$ (corresponding electrical parameters: $R_{\text {bulk }}$ and $Z_{W}$ in Figure 13) and charge separation within the film of sensitized RDS oxide (corresponding electrical parameter: $C_{\mathrm{SC}}$ in Figure 13). 


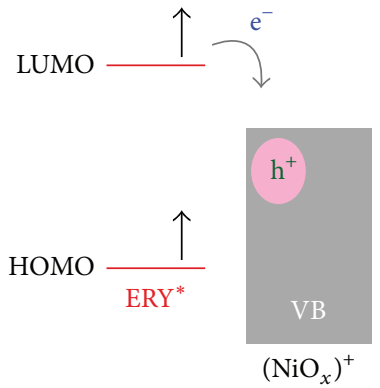

(a)

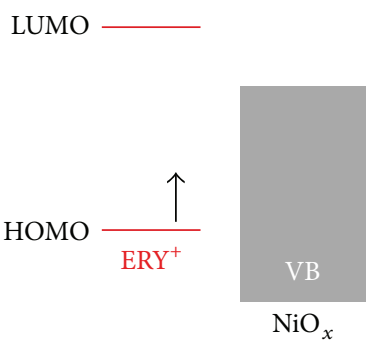

(b)

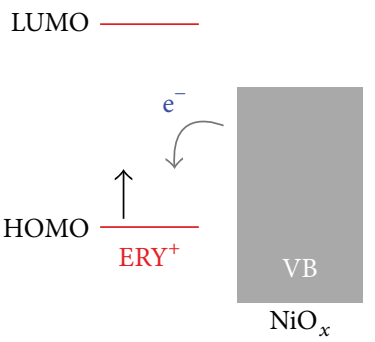

(c)

FIGURE 25: Hypothesis of mechanism of electrochemically induced charge injection from photoexcited ERY sensitizer to mesoporous RDS/CS $\mathrm{NiO}_{x}$ within the potential range of $\mathrm{NiO}_{x}$ oxidation $\left(2.8-3.7 \mathrm{~V}\right.$ versus $\mathrm{Li}^{+} / \mathrm{Li}$ ). (a) Electron is injected in the valence band (VB) of oxidized $\mathrm{RDS} / \mathrm{CS} \mathrm{NiO}$ from excited ERY colorant; (b) upon neutralization of the hole that has been electrochemically injected in $\mathrm{NiO}_{x}$ the colorant ERY would retain a positive charge with formation of the combination $\mathrm{ERY}^{+}-\mathrm{NiO}_{x}$. (c) $\mathrm{NiO}_{x}$ can regenerate the hole by back donation of an electron from the VB of neutral $\mathrm{NiO}_{x}$ to the HOMO of ERY ${ }^{+}$. Further electrochemical oxidation of $\mathrm{NiO}_{x}$ can occur also when the dye sensitizer is in the oxidized state (not shown).

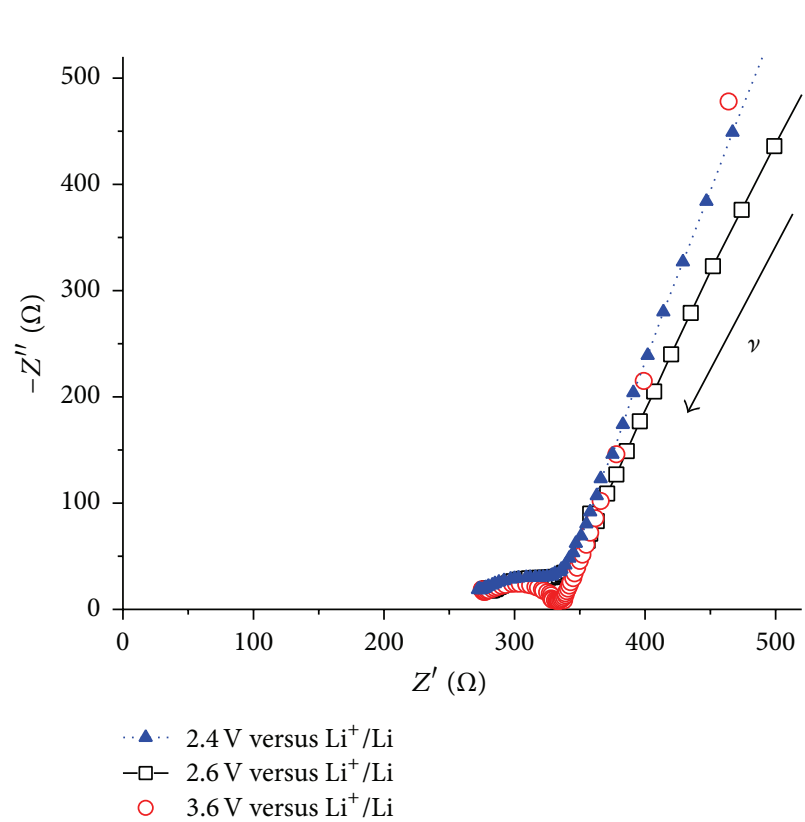

(a)

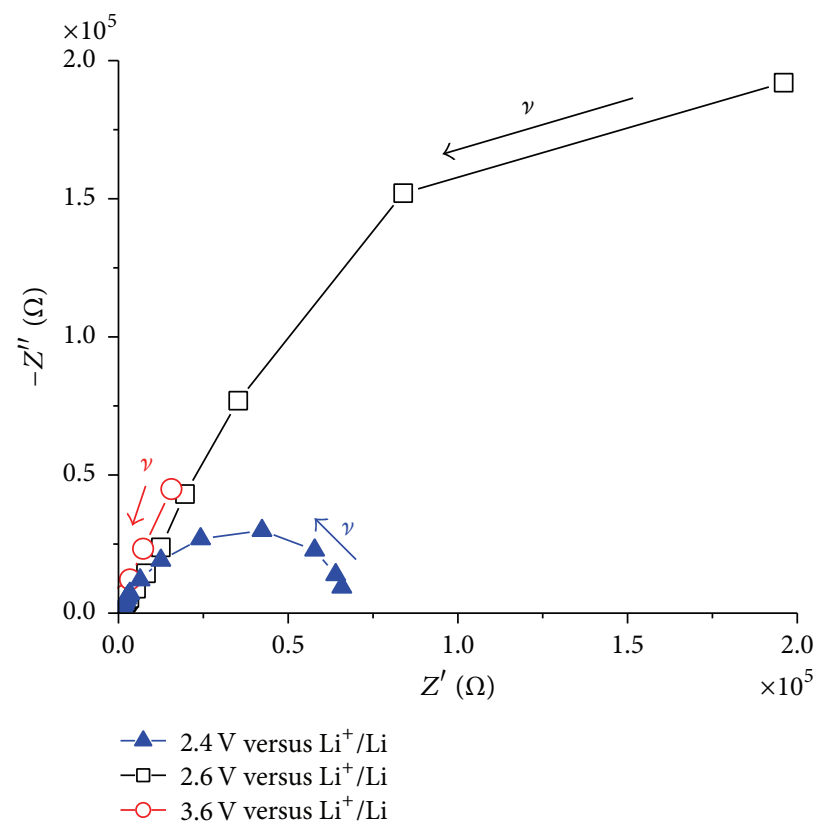

(b)

FIGURE 26: Electrochemical impedance spectra of ERY-sensitized CS $\mathrm{NiO}_{x}$ polarized at different values of applied potential (see inset). Spectra have been recorded in dark conditions and displayed as Nyquist plots ((a) small scale; (b) large scale). NiO film thickness: $0.3 \mu \mathrm{m}$; substrate: ITO. Arrows indicate the direction of increase for the frequency of polarization.

3.4. -DSCs with ERY-Sensitized CS/RDS NiO as Photoactive Cathodes. ERY-sensitized CS and RDS $\mathrm{NiO}_{x}$ on ITO have been utilized as photocathodes in p-DSCs utilizing platinized fluorine-doped tin oxide (FTO) as counter electrode and a solution of the redox couple $\mathrm{I}_{3}{ }^{-} / \mathrm{I}^{-}$in acetonitrile as electrolyte. Photocathode and the counter electrode had the same electroactive area of $0.25 \mathrm{~cm}^{2}$ in the assembled p-DSC. The p-DSC based on ERY-sensitized CS $\mathrm{NiO}_{x}$ displayed overall efficiency $\eta=0.014 \%$ with open circuit voltage $V_{\mathrm{OC}}=0.11 \mathrm{~V}$, cathodic short circuit current density $J_{\mathrm{SC}}=0.353 \mathrm{~mA} \mathrm{~cm}^{-2}$, and fill factor $\mathrm{FF}=0.35$ when $I_{\text {in }}=1000 \mathrm{~W} \mathrm{~m}^{-2}$ and $\mathrm{CS} \mathrm{NiO} \mathrm{N}_{x}$ film thickness was $0.6 \mu \mathrm{m}$. The characteristic curve of the $\mathrm{p}$ DSC with ERY-sensitized RDS $\mathrm{NiO}_{x}$ is shown in Figure 29. The relevant parameters of the $\mathrm{RDS} \mathrm{NiO}_{x}$ based p-DSC are $V_{\mathrm{OC}}=0.126 \mathrm{~V}$; cathodic $J_{\mathrm{SC}}=0.263 \mathrm{~mA} \mathrm{~cm}^{-2} ; \mathrm{FF}=39 \%$; $\eta: 0.015 \%$.

These results show clearly a considerable improvement of the $J V$ characteristic curves of CS and RDS oxide samples if compared to that of sol-gel prepared $\mathrm{NiO}_{x}$ films sensitized with the same ERY dye [9]. For the latter system it was found that $V_{\mathrm{OC}}=0.083 \mathrm{~V}$, cathodic $J_{\mathrm{SC}}=0.2 \mathrm{~mA} \mathrm{~cm}^{-2}, \mathrm{FF}=0.27$, and $\eta=0.0076 \%$ when $1 \mu \mathrm{m}$ thick sol-gel $\mathrm{NiO}_{x}$ was tested. 


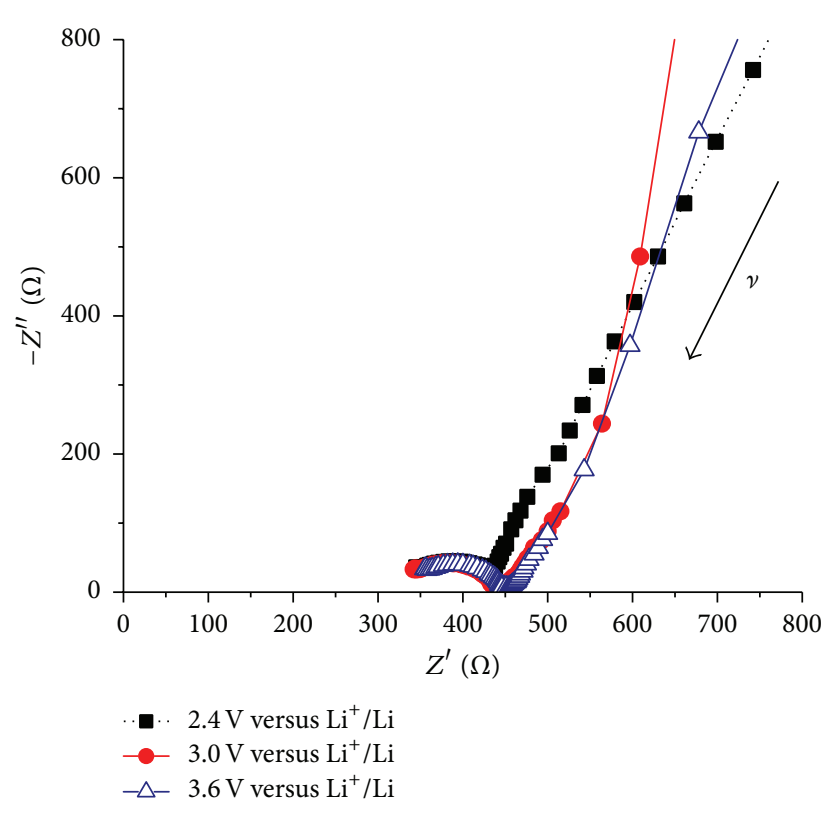

(a)

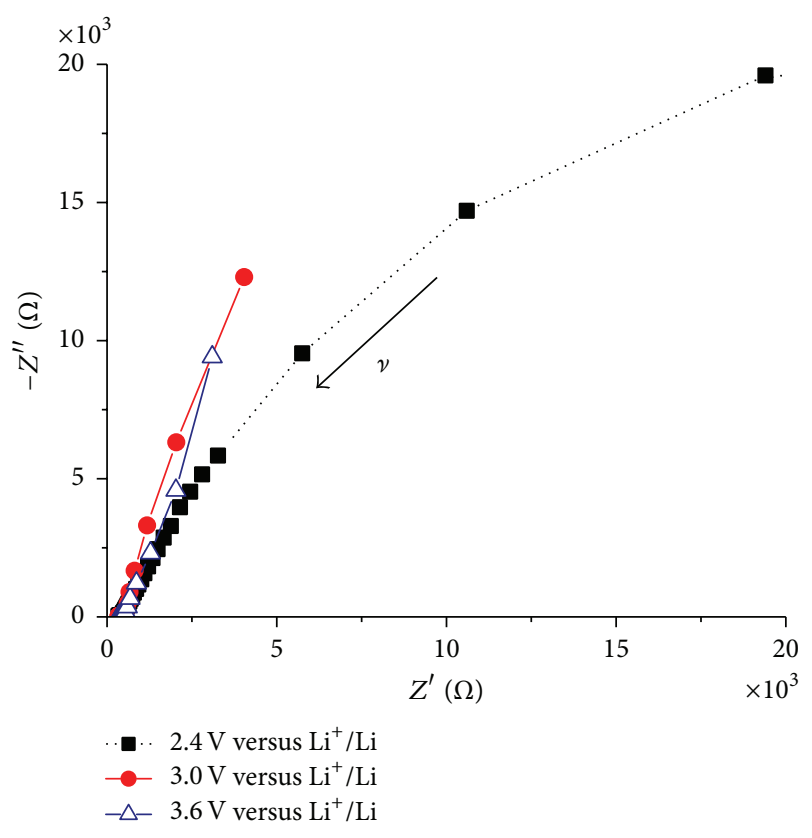

(b)

FIGURE 27: Electrochemical impedance spectra of ERY-sensitized $\mathrm{RDS} \mathrm{NiO}_{x}$ polarized at different values of applied potential (see inset). Spectra have been recorded in dark conditions and displayed as Nyquist plots ((a) small scale; (b) large scale). NiO film thickness: $0.3 \mu \mathrm{m}$; substrate: ITO. Arrows indicate the direction of increase for the frequency of polarization.

The ameliorants here reported are ascribed to the higher efficiency of sensitization in the CS and RDS $\mathrm{NiO}_{x}$ films for their enhanced mesoporosity (Figure 22) with respect to sol-gel $\mathrm{NiO}_{x}$ [9]. Another favorable aspect of CS and RDS methods is the achievement of metal oxide samples with higher electronic quality in terms of electrical connectivity between sintered nanoparticles and between CS/RDS $\mathrm{NiO}_{x}$ layer and ITO substrate. These improvements are attained by sintering preformed nanoparticles of metal oxide from a suspension and not from heating a solution of metal oxide precursors like the case of sol-gel methods $[9,45,46]$.

\section{Conclusions}

$\mathrm{NiO}_{x}$ coatings deposited on ITO via sintering of oxide nanoparticles at $\sim 400^{\circ} \mathrm{C}$ with conventional furnace (CS method) and plasma assisted microwave heating (RDS method) have been obtained in the configuration of thin films $(l<3 \mu \mathrm{m})$ with mesoporous features. Their electrochemi$\mathrm{cal} /$ photoelectrochemical properties have been studied when $\mathrm{NiO}_{x}$ was in the bare and sensitized states. The sensitizer here adopted was the commercial benchmark erythrosine B (ERY B). It is here confirmed that ITO constitutes an electroactive substrate since it undergoes an irreversible redox process of reduction at $1.2 \mathrm{~V}$ versus $\mathrm{Li}^{+} / \mathrm{Li}$. For this reason we could characterize the electrochemical behavior of $\mathrm{NiO}_{x}$ thin films only at potential values that involved the sole oxidation of $\mathrm{NiO}_{x}$ but not its reduction when ITO was the technical substrate. The oxidation of bare CS/RDS $\mathrm{NiO}_{x}$ coatings represents a solid state redox process which is surface confined and not diffusion controlled. This is also the case for the $\mathrm{NiO}_{x}$ films sensitized with ERY B. In the sole case of the RDS sample, the film of oxide requires a preliminary stadium of electrochemical activation consisting in the continuous cycling of the applied potential between the values at which $\mathrm{RDS} \mathrm{NiO}_{x}$ is in the neutral and fully oxidized states (range $2.4-3.7 \mathrm{~V}$ versus $\mathrm{Li}^{+} / \mathrm{Li}$ ). Since electrochemical activation was required also for the ERY-sensitized version of $\mathrm{RDS} \mathrm{NiO} x$ we conclude that the nature of the electrochemical process occurring in the potential window $2.4-3.7 \mathrm{~V}$ versus $\mathrm{Li}^{+} / \mathrm{Li}$ does not get affected by the presence of ERY and is represented exclusively by the oxidation of RDS $\mathrm{NiO}_{x}$. The electrochemical impedance spectra have been recorded for CS/RDS $\mathrm{NiO}_{x}$ in both bare and ERY-sensitized versions. Depending on the range of applied frequencies of stimulus we could identify a process of charge transfer at the $\mathrm{NiO}_{x}$ electrode/electrolyte interface that is not affected by the extent of polarization, status of sensitization, or status of illumination and a second process of charge transport through the metal oxide layer with a resistance inversely proportional to the concentration of the electrochemically injected charge carriers. The latter parameter is heavily affected by the applied potential, and by the status of illumination for ERY-sensitized $\mathrm{NiO}_{x}$, whereas the status of sensitization does not seem to play a major role in the determination of charge carriers concentration in dark conditions. When CS/RDS $\mathrm{NiO}_{x}$ is in the fully oxidized state a finite thickness effect could be evidenced in the corresponding EIS profiles denoting a state of high conductivity for $\mathrm{NiO}_{x}$ deposited onto ITO. Since CS/RDS $\mathrm{NiO}_{x}$ oxidation is a solid state redox process, the charge carriers of oxidized $\mathrm{NiO}_{x}$ have a double nature, 


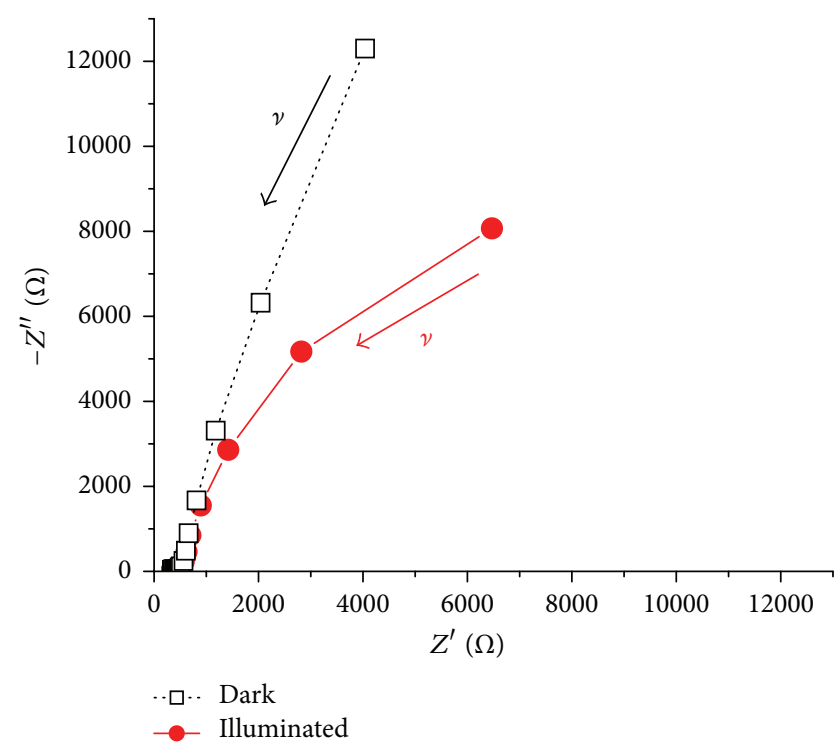

FIGURE 28: Electrochemical impedance spectra of ERY-sensitized RDS NiO in dark conditions and irradiated with white light (source: halogen lamp with $I_{\text {in }}=28.6 \mathrm{~W} \mathrm{~cm}^{-2}$ ). Spectra have been displayed as Nyquist plots. $\mathrm{NiO}$ film thickness: $0.3 \mu \mathrm{m}$; substrate: ITO. ERYsensitized RDS NiO sample was polarized at $3.0 \mathrm{~V}$ versus $\mathrm{Li}^{+} / \mathrm{Li}$ during the recording of both spectra. Arrows indicate the direction of increase for the frequency of polarization.

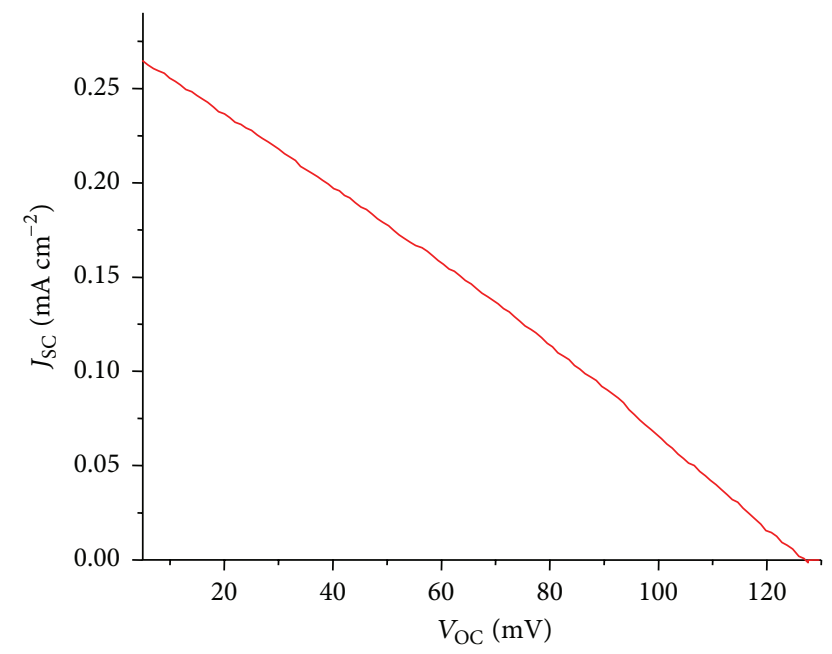

FIGURE 29: $J V$ curve of the p-DSC having ERY-sensitized RDS $\mathrm{NiO}_{x}$ on ITO as photoactive cathode. NiO film thickness: $0.3 \mu \mathrm{m} ; I_{\text {in }}=$ $870 \mathrm{~W} \mathrm{~m}^{-2}$.

that is, electronic and ionic, with ions that are taken up by $\mathrm{NiO}_{x}$ to compensate the variations of the redox state of $\mathrm{NiO}_{x}$. Under these circumstances the diffusion of coupled charge carriers through oxidized $\mathrm{NiO}_{x}$ should be considered in order to accomplish an appropriate analysis of the EIS features for type of system. Anyhow, the quantitative analysis of the EIS signals of bare and ERY-sensitized CS/RDS $\mathrm{NiO}_{x}$ produced in dark conditions and under illumination was beyond the scopes of the present contribution and only a qualitative analysis of the EIS signals was accounted for in this paper. The CS/RDS $\mathrm{NiO}_{x}$-based DSCs were assembled. Our devices displayed an improved $J V$ performance with respect to the $\mathrm{NiO}_{x}$ samples sensitized with the same dye but prepared with wet, not scalable, methods (overall efficiency $\eta_{\text {CS/RDS }}=0.014 / 5 \%$ versus $\left.\eta_{\text {sol-gel }}=0.008 \%\right)$. The improvements here reported are mainly ascribed to the better efficiency of sensitization/hole injection for CS/RDS $\mathrm{NiO}_{x}$ with respect to sol-gel samples with comparable thickness. This is a consequence of the enhanced mesoporosity of $\mathrm{NiO}_{x}$ films obtained from the sintering of preformed nanoparticles. Another factor of improvement related to the employment of CS/RDS methods was the better quality of the electrical contact between sintered metal oxide nanoparticles and at the $\mathrm{NiO}_{x} /$ ITO interface.

\section{Conflict of Interests}

The authors declare that there is no conflict of interests regarding the publication of this paper.

\section{Acknowledgment}

The authors thank Dr. Francesco Mura for the realization of tin oxide SEM pictures and his profitable help in their analysis.

\section{References}

[1] S. R. Nalage, M. A. Chougule, S. Sen, P. B. Joshi, and V. B. Patil, "Sol-gel synthesis of nickel oxide thin films and their characterization," Thin Solid Films, vol. 520, no. 15, pp. 48354840, 2012.

[2] S. P. Mitoff, "Electrical conductivity and thermodynamic equilibrium in nickel oxide," The Journal of Chemical Physics, vol. 35, no. 3, pp. 882-889, 1961.

[3] L. D’Amario, G. Boschloo, A. Hagfeldt, and L. Hammarström, "Tuning of conductivity and density of states of $\mathrm{NiO}$ mesoporous films used in p-type DSSCs," Journal of Physical Chemistry C, vol. 118, no. 34, pp. 19556-19564, 2014.

[4] M. Awais, M. Rahman, J. M. Don MacElroy et al., "Deposition and characterization of $\mathrm{NiO}_{x}$ coatings by magnetron sputtering for application in dye-sensitized solar cells," Surface and Coatings Technology, vol. 204, no. 16-17, pp. 2729-2736, 2010.

[5] M. Awais, D. Dini, J. M. Don MacElroy, Y. Halpin, J. G. Vos, and D. P. Dowling, "Electrochemical characterization of $\mathrm{NiO}$ electrodes deposited via a scalable powder microblasting technique," Journal of Electroanalytical Chemistry, vol. 689, pp. 185-192, 2013.

[6] M. Awais, D. D. Dowling, M. Rahman, J. G. Vos, F. Decker, and D. Dini, "Spray-deposited $\mathrm{NiO}_{x}$ films on ITO substrates as photoactive electrodes for p-type dye-sensitized solar cells," Journal of Applied Electrochemistry, vol. 43, no. 2, pp. 191-197, 2013.

[7] M. Awais, M. Rahman, J. M. Don MacElroy, D. Dini, J. G. Vos, and D. P. Dowling, "Application of a novel microwave plasma treatment for the sintering of nickel oxide coatings for use in dye-sensitized solar cells," Surface and Coatings Technology, vol. 205, no. 2, pp. S245-S249, 2011. 
[8] G. Boschloo and A. Hagfeldt, "Spectroelectrochemistry of nanostructured NiO," The Journal of Physical Chemistry B, vol. 105, pp. 3039-3044, 2001.

[9] J. He, H. Lindström, A. Hagfeldt, and S. E. Lindquist, "Dyesensitized nanostructured p-type nickel oxide film as a photocathode for a solar cell," The Journal of Physical Chemistry B, vol. 103, no. 42, pp. 8940-8943, 1999.

[10] C. G. Granqvist, "Transparent conductors as solar energy materials: a panoramic review," Solar Energy Materials and Solar Cells, vol. 91, no. 17, pp. 1529-1598, 2007.

[11] M. Hajzeri, A. Šurca Vuk, L. Slemenik Perše et al., "Solgel vanadium oxide thin films for a flexible electronically conductive polymeric substrate," Solar Energy Materials and Solar Cells, vol. 99, pp. 62-72, 2012.

[12] B. O’Regan and M. Grätzel, "A low-cost, high-efficiency solar cell based on dye-sensitized colloidal $\mathrm{TiO}_{2}$ films," Nature, vol. 353, no. 6346, pp. 737-740, 1991.

[13] J. He, H. Lindström, A. Hagfeldt, and S.-E. Lindquist, "Dyesensitized nanostructured tandem cell-first demonstrated cell with a dye-sensitized photocathode," Solar Energy Materials and Solar Cells, vol. 62, no. 3, pp. 265-273, 2000.

[14] L. Li, E. A. Gibson, P. Qin et al., "Double-layered NiO photocathodes for p-Type DSSCs with record IPCE," Advanced Materials, vol. 22, no. 15, pp. 1759-1762, 2010.

[15] A. Nattestad, A. J. Mozer, M. K. R. Fischer et al., "Highly efficient photocathodes for dye-sensitized tandem solar cells," Nature Materials, vol. 9, no. 1, pp. 31-35, 2010.

[16] S. Powar, T. Daeneke, M. T. Ma et al., "Highly efficient p-type dye-sensitized solar cells based on tris(1,2diaminoethane)cobalt(II)/(III) electrolytes," Angewandte Chemie-International Edition, vol. 52, no. 2, pp. 602-605, 2013.

[17] Y. Mizoguchi and S. Fujihara, "Fabrication and dye-sensitized solar cell performance of nanostructured $\mathrm{NiO} /$ coumarin 343 photocathodes," Electrochemical and Solid-State Letters, vol. 11, no. 8, pp. K78-K80, 2008.

[18] E. A. Gibson, A. L. Smeigh, L. Le Pieux et al., "A p-type NiObased dye-sensitized solar cell with an open-circuit voltage of 0.35 v," Angewandte Chemie-International Edition, vol. 48, no. 24, pp. 4402-4405, 2009.

[19] M. S. Wu and M. J. Wang, "Nickel oxide film with open macropores fabricated by surfactant-assisted anodic deposition for high capacitance supercapacitors," Chemical Communications, vol. 46, no. 37, pp. 6968-6970, 2010.

[20] I. A. Garduño, J. C. Alonso, M. Bizarro, R. Ortega, L. RodrguezFernndez, and A. Ortiz, "Optical and electrical properties of lithium doped nickel oxide films deposited by spray pyrolysis onto alumina substrates," Journal of Crystal Growth, vol. 312, no. 22, pp. 3276-3281, 2010.

[21] F. Vera, R. Schrebler, E. Muñoz et al., "Preparation and characterization of Eosin B- and Erythrosin J-sensitized nanostructured NiO thin film photocathodes," Thin Solid Films, vol. 490, no. 2, pp. 182-188, 2005.

[22] A. Nattestad, M. Ferguson, R. Kerr, Y.-B. Cheng, and U. Bach, "Dye-sensitized nickel(II)oxide photocathodes for tandem solar cell applications," Nanotechnology, vol. 19, no. 29, Article ID 295304, 2008.

[23] M. Awais, Deposition and evaluation of nickel oxide coatings for dye-sensitized solar cell application [Ph.D. thesis], School of Electrical, Electronic and Mechanical Engineering, University College Dublin (UCD), Dublin, Ireland, 2011.
[24] M. L. McConnell, D. P. Dowling, C. Pope, K. Donnelly, A. G. Ryder, and G. M. O'Connor, "High pressure diamond and diamond-like carbon deposition using a microwave CAP reactor," Diamond and Related Materials, vol. 11, no. 3-6, pp. 1036-1040, 2002.

[25] J. Halme, J. Saarinen, and P. Lund, "Spray deposition and compression of $\mathrm{TiO}_{2}$ nanoparticle films for dye-sensitized solar cells on plastic substrates," Solar Energy Materials and Solar Cells, vol. 90, no. 7-8, pp. 887-899, 2006.

[26] S. F. Cogan, E. J. Anderson, T. D. Plante, and R. D. Rauh, "Electrochemical investigation of electrochromism in transparent conductive oxides," Applied Optics, vol. 24, no. 15, pp. 22822283, 1985.

[27] S. Passerini and B. Scrosati, "Characterization of nonstoichiometric nickel oxide thin-film electrodes," Journal of the Electrochemical Society, vol. 141, no. 4, pp. 889-895, 1994.

[28] Z. Wang and X. Hu, "Structural and electrochemical characterization of 'open-structured' ITO films," Thin Solid Films, vol. 392, no. 1, pp. 22-28, 2001.

[29] D. Dini and F. Decker, "Stress in thin films of metal oxide electrodes for intercalation reactions," Electrochimica Acta, vol. 43, no. 19-20, pp. 2919-2923, 1998.

[30] C. Ho, I. D. Raistrick, and R. A. Huggins, "Application of A-C techniques to the study of lithium diffusion in tungsten trioxide thin films," Journal of the Electrochemical Society, vol. 127, no. 2, pp. 343-349, 1980.

[31] H. Gerischer and R. McIntyre, "A study of the charge and potential distribution at the semiconductor/electrolyte interface for the condition of degeneracy," The Journal of Chemical Physics, vol. 83, no. 3, pp. 1363-1370, 1985.

[32] L. Chernyak, V. Lyakhovitskaya, S. Richter et al., "Electronic effects of ion mobility in semiconductors: mixed electronicionic behavior and device creation in Si:Li," Journal of Applied Physics, vol. 80, no. 5, pp. 2749-2762, 1996.

[33] H. Gerischer, "The impact of semiconductors on the concepts of electrochemistry," Electrochimica Acta, vol. 35, no. 11-12, pp. 1677-1699, 1990.

[34] R. Schöllhorn, "Intercalation chemistry," Physica B, vol. 99, no. 1-4, pp. 89-99, 1980.

[35] S. Rebouillat, M. E. G. Lyons, M. P. Brandon, and R. L. Doyle, "Paving the way to the integration of smart nanostructures: part II: nanostructured microdispersed hydrated metal oxides for electrochemical energy conversion and storage applications," International Journal of Electrochemical Science, vol. 6, pp. 58305917, 2011.

[36] M. S. Whittingham, "Chemistry of intercalation compounds: metal guests in chalcogenide hosts," Progress in Solid State Chemistry, vol. 12, no. 1, pp. 41-99, 1978.

[37] A. J. Bard and L. R. Faulkner, Electrochemical Methods, Fundamentals and Applications, John Wiley, New York, NY, USA, 2nd edition, 2001.

[38] J. Bisquert, "Influence of the boundaries in the impedance of porous film electrodes," Physical Chemistry Chemical Physics, vol. 2, no. 18, pp. 4185-4192, 2000.

[39] J. Bisquert, "Theory of the impedance of electron diffusion and recombination in a thin layer," Journal of Physical Chemistry B, vol. 106, no. 2, pp. 325-333, 2002.

[40] B. A. Gregg, "Interfacial processes in the dye-sensitized solar cell," Coordination Chemistry Reviews, vol. 248, no. 13-14, pp. 1215-1224, 2004. 
[41] A. Zaban, S. Ferrere, and B. A. Gregg, "Relative energetics at the semiconductor/sensitizing dye/electrolyte interface," The Journal of Physical Chemistry B, vol. 102, no. 2, pp. 452-460, 1998.

[42] H. Gerischer and F. Willig, "Reaction of excited dye molecules at electrodes," in Physical and Chemical Applications of Dyestuffs, vol. 61 of Topics in Current Chemistry, pp. 31-84, Springer, Berlin, Germany, 1976.

[43] Z. Hongjun, A. Hagfeldt, and G. Boschloo, "Photoelectrochemistry of mesoporous $\mathrm{NiO}$ electrodes in iodide/triiodide electrolytes," Journal of Physical Chemistry C, vol. 111, no. 47, pp. 17455-17458, 2007.

[44] B. A. Gregg, A. Zaban, and S. Ferrere, "Dye sensitized solar cells: energetic considerations and applications," Zeitschrift für Physikalische Chemie, vol. 212, no. 1, pp. 11-22, 1999.

[45] A. Nakasa, H. Usami, S. Sumikura, S. Hasegawa, T. Koyama, and E. Suzuki, "A high voltage dye-sensitized solar cell using a nanoporous $\mathrm{NiO}$ photocathode," Chemistry Letters, vol. 34, no. 4, pp. 500-501, 2005.

[46] Z. Jiao, M. Wu, Z. Qin, and H. Xu, "The electrochromic characteristics of sol-gel-prepared $\mathrm{NiO}$ thin film," Nanotechnology, vol. 14, no. 4, article 458, 2003. 

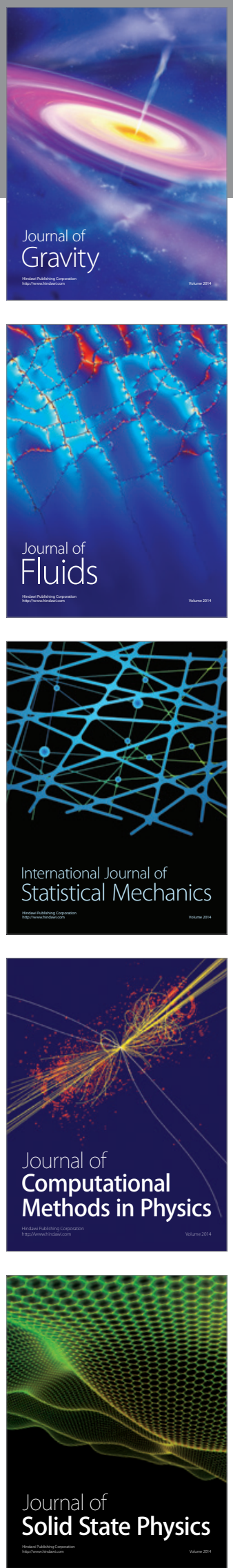

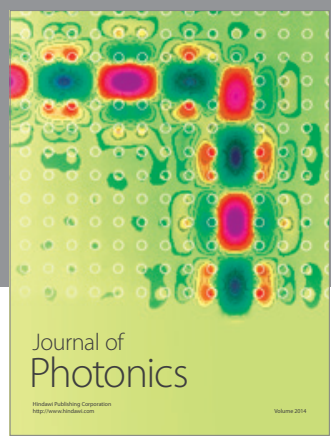

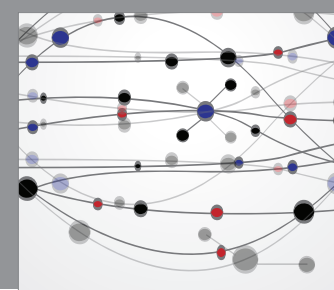

The Scientific World Journal

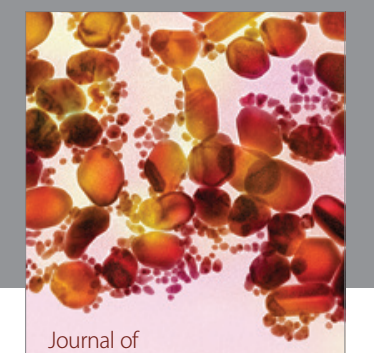

Soft Matter
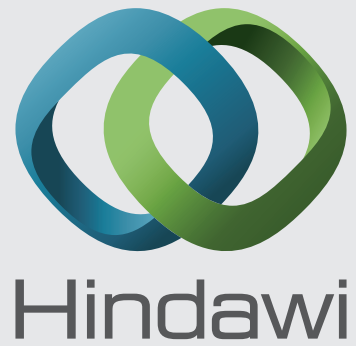

Submit your manuscripts at

http://www.hindawi.com
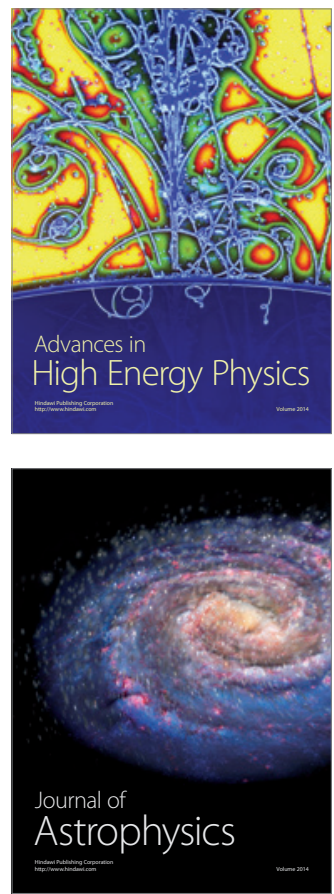
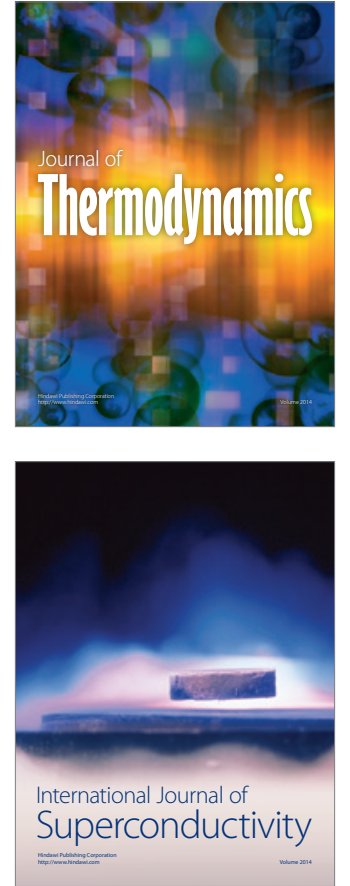
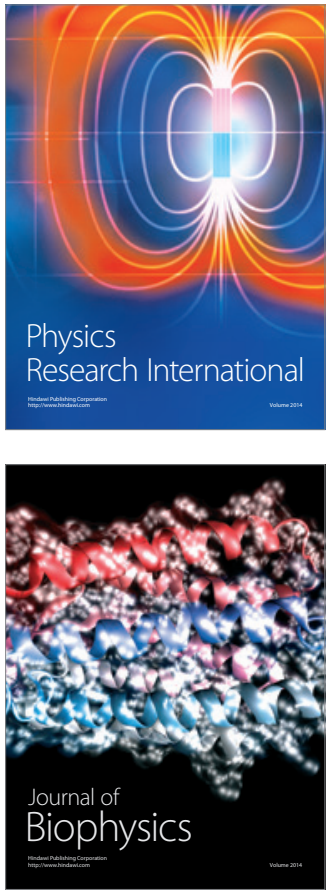
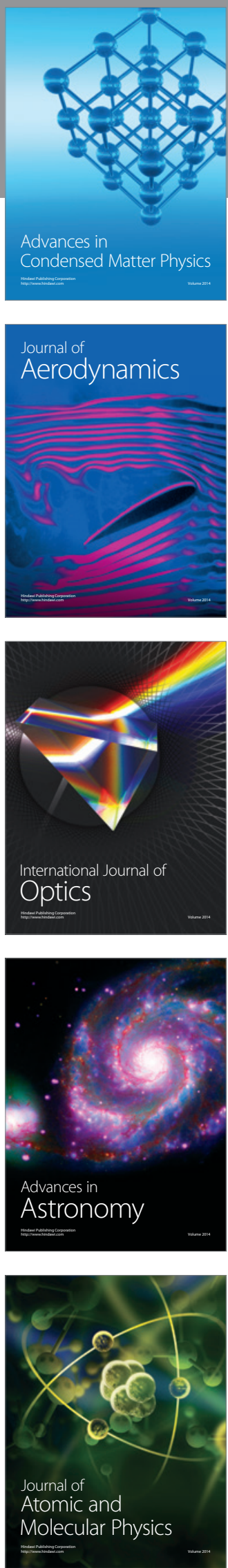